Document downloaded from:

http://hdl.handle.net/10251/150362

This paper must be cited as:

Badia, J.; Ribes-Greus, A. (2016). Mechanical recycling of polylactide, upgrading trends and combination of valorization techniques. European Polymer Journal. 84:22-39. https://doi.org/10.1016/j.eurpolymj.2016.09.005

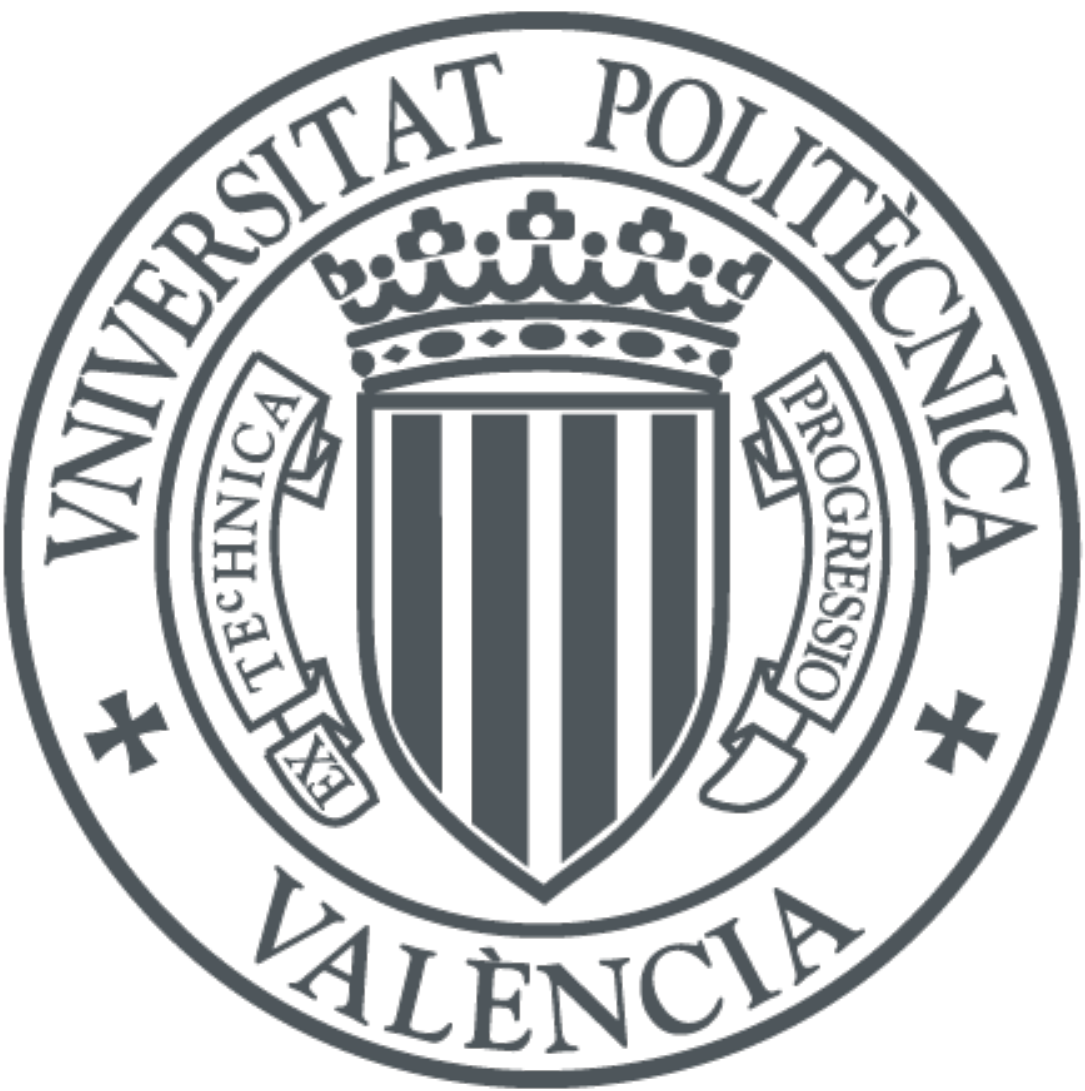

The final publication is available at

https://doi.org/10.1016/j.eurpolymj.2016.09.005

Copyright Elsevier

Additional Information 


\title{
MECHANICAL RECYCLING OF POLYLACTIDE, UPGRADING TRENDS AND COMBINATION OF VALORISATION TECHNIQUES
}

\author{
J.D. Badia ${ }^{1,2, *}$, A. Ribes-Greus ${ }^{1}$
}

This is an open-access version, according to http://www.sherpa.ac.uk/romeo/issn/0014-3057/es/

Full text available at http://www.sciencedirect.com/science/article/pii/S0014305716306772

DOI: http://doi.org/10.1016/j.eurpolymj.2016.09.005

Please, cite it as:

J.D. Badia, A. Ribes-Greus. Mechanical recycling of polylactide, upgrading trends and combination of valorisation techniques. European Polymer Journal, 2016; 84:22-39

${ }^{1}$ Instituto de Tecnología de Materiales.

Universitat Politècnica de València.

Camí de Vera, s/n, 46022 València, Spain

${ }^{2}$ Departament d’ Enginyeria Química.

Escola Tècnica Superior d’ Enginyeria.

Universitat de València. Av. de la Universitat, s/n,46100, Burjassot, Spain

Corresponding author: José-David Badia, jdbadia@itm.upv.es 


\title{
MECHANICAL RECYCLING OF POLYLACTIDE, UPGRADING TRENDS AND COMBINATION OF VALORISATION TECHNIQUES
}

\section{J.D. Badia ${ }^{1,2, *}$, A. Ribes-Greus ${ }^{1}$}

\begin{abstract}
The upcoming introduction of polylactides in the fractions of polymer waste encourages technologists to ascertain its valorization at the best quality conditions. Mechanical recycling of PLA represents one of the most cost-effective methodologies, but the recycled materials are usually directed to downgraded applications, due to the inherent thermo-mechanical degradation affecting its mechanical, thermal and rheological performance. In this review, the current state of mechanical recycling of PLA is reported, with special emphasis on a multi-scale comparison among different studies. Additionally, the applications of physical and chemical upgrading strategies, as well as the chances to blend and/or composite recycled PLA are considered. Moreover, the different valorization techniques that can be combined to optimize the value of PLA goods along its life cycle are discussed. Finally, a list of different opportunities to nurture the background of the mechanical recycling of PLA is proposed, in order to contribute to the correct waste management of PLA wastes.
\end{abstract}

\section{KEYWORDS}

recycling; reprocessing; valorization; biopolymer; polylactide (PLA); degradation; upgrading; review 
J.D. Badia, A. Ribes-Greus. Mechanical recycling of polylactide, upgrading trends and combination of valorisation techniques. European Polymer Journal, 2016; 84:22-39

\section{List of Abbreviations}

$\left[\mathrm{LA}_{\mathrm{C}}\right]_{\mathrm{n}} \quad$ Cyclic PLA oligomer

$\left[\mathrm{LA}_{\mathrm{L}}\right]_{\mathrm{n}} \quad$ Linear PLA oligomer

$\Delta \mathrm{h}_{\mathrm{CC}} \quad$ Specific Cold-crystallization enthalpy

AFM Atomic Force Microscopy

D fragility parameter

DETA Dielectric Thermal Analysis

DMTA Dynamic Mechanical-Thermal Analysis

DSC Differential Scanning Calorimetry

EOL $\quad$ End of Life

FT-IR Fourier-Transform InfraRed Scpectroscopy

GC Gas Chromatography

GPC Gel Permeation Chromatography (see also SEC)

GWP Global Warming Potential

HDT Heat Deflection Temperature

HPLC High Performance Liquid Chromatography

LCA life cycle assessment

LMWC Low molecular weight compounds

MALDI Matrix-Assisted Laser Desorption/Ionization

MFR Melt-Mass Flow Rate

Mn Average molar mass in number

MS Mass Spectrometry

MV Viscous molar mass

NMR Nuclear Magnetic Resonance 
J.D. Badia, A. Ribes-Greus. Mechanical recycling of polylactide, upgrading trends and combination of valorisation techniques. European Polymer Journal, 2016; 84:22-39

\begin{tabular}{|c|c|}
\hline OIT & Oxidation Induction Time \\
\hline OT & Oxygen Transport \\
\hline $\mathrm{PE}$ & Polyethylene \\
\hline PET & poly(ethylene terephthalate) \\
\hline PHA & poly(hydroxyalcanoate) \\
\hline PLA & polylactide or poly(lactic acid) \\
\hline POM & Polarized Optical Microscopy \\
\hline PS & Polystyrene \\
\hline PVC & Poly(vynil chloride) \\
\hline Py & Pyrolysis \\
\hline $\mathrm{Ri}$ & reprocessing cycle number "i" \\
\hline RPLA-i & PLA reprocessed "i" times \\
\hline RWF & recycled wood fiber \\
\hline SEC & Size Exclusion Chromatography (see also GPC) \\
\hline SEM & Scanning Electron Microscopy \\
\hline$\sigma_{\mathrm{B}}$ & stress at break \\
\hline$\sigma_{\mathrm{T}}$ & tensile strength \\
\hline $\mathrm{T}_{\mathrm{CC}}$ & Cold-crystallization temperature \\
\hline TDB & Thermal Decomposition Behaviour \\
\hline TEM & Transmission Electron Microscopy \\
\hline $\mathrm{T}_{\mathrm{g}}$ & Glass transition temperature \\
\hline $\operatorname{tg}(\delta)$ & tangent of delta, from DMTA \\
\hline TGA & Thermogravimetric Analysis \\
\hline $\mathrm{T}_{1}$ & Melting temperature \\
\hline
\end{tabular}


J.D. Badia, A. Ribes-Greus. Mechanical recycling of polylactide, upgrading trends and combination of valorisation techniques. European Polymer Journal, 2016; 84:22-39

TOF Time-of-Flight

Tox Temperature of Oxidation

UV Ultra-violet

V Virgin

VFTH Vogel-Fulcher-Tamann-Hesse

VPLA Virgin PLA

WVT Water vapour transport

$\mathrm{X}_{\mathrm{C}} \quad$ Crystallinity degree

ZDT Zero-Decomposition temperature 


\section{FRAMEWORK OF THE REVIEW}

Short-time applications from bio-based and biodegradable[1] plastics have attracted much interest [2] in different industrial, social and economic sectors ranging from biomedical applications for their use in surgery [3], as sutures, tissues or scaffolds; pharmacology [4] as drug carriers [5], and packaging, as containers [6] for drinkable liquids [7] or cosmetics. One of the key reasons driving this growing interest is the incompatibility of the non-renewable polymeric waste with the environment where they are disposed after their use. The efforts have been therefore focused on the development of novel biodegradable polymers satisfying the requirement of degradability, compatibility with the disposal environment and the release of low-toxicity degradation products[8]. In fact, a trend to derive more carbon from the renewable resources to preserve the ecosystem can be found, moving from the petrochemical industry to fermentation and genetic engineering options, in a cost-effective and ecologically sustainable framework [8]. However, after the evaluation of the sustainability of biobased plastics, it is generally concluded that none of those currently in commercial use or under development are fully sustainable. Some bio-based plastics are preferable from a health and safety perspective and others from an environmental perspective. In general, polymers such as polylactides (PLA)s, poly(hydroxyalcanoate)s (PHA)s or starch-based polymers are commonly chosen over other bio-based polymers [9].

Polylactides (PLA) are thermoplastic polyesters obtained from the ring-opening polymerization of lactide, which may be derived from the fermentation of sugar feedstocks at competitive prices compared to those previously achievable from petrochemical derived products [10], [11]. PLAs have numerous interesting properties including good processability, mechanical properties, thermal stability and low environmental impact [12]. In particular, PLA stands out as an alternative to substitute commodities in well-established sectors. Such could be the case of the replacement of poly(ethylene terephthalate) (PET) bottles in the packaging industry [13]. Actually, a comparative assessment of the environmental profile of PLA and PET for drinking water bottles from a life cycle assessment (LCA) perspective showed that the environmental performance of PLA bottles was better than that of PET bottles in terms of global warming potential (GWP), reduction of dependency on fossil energy, and decrease of human toxicity [14]. The end of life (EoL) is not always considered in LCA, nevertheless, those reports that included it described much higher GWP results than those which limited 
the scope to the stage of the production of resins or pellets. Including EoL in the LCA provides more comprehensive results for bio-based polymers, but simultaneously introduces greater amounts of uncertainty and variability. Although there is little LCA data available on the impacts of different manners of disposal, it has been argued that it would be critical for future sustainability assessments [15].

The necessary implementation of unit operations during the dismantling process, new separation technologies, and the logistics of handling additional streams of material will require further studies, developments, and monitoring, in order to develop more robust and effective recovery methods [16]. As well, it is known that bio-based materials are suitable for biological waste treatment trough composting, thus having a great potential to contribute to the reduction of the amount of waste sent to landfill and generating valuable soil improvers, which is of great importance for industries, governments and consumers [17]. However, the presumably high amount of bio-based plastic waste surpassing the capability of composting facilities has to be taken into account [13]. In this sense, to explore the chances of enhancing the valorization of PLA goods, by means of material/mechanical or chemical/energy methods would be advisable, thus strengthening the possibilities of extending their service lives and or obtain an added value before finally discarding them into bio-disposal facilities[18].

Previous reviews have been focused on the different possibilities of general recycling of plastic waste [18] and bioplastics, their blends and biocomposites by means of mechanical and chemical methods[19]. In this review, a deep focus is given to the mechanical recycling of polylactide, blends, and composites thereof, with emphasis on the connection between molecular-level variations and macroscopic performance of recyclates. In addition, the different valorization techniques that can be combined to optimize the value of PLA goods along its life-cycle are discussed. Finally, a list of different opportunities to nurture the background of the mechanical recycling of PLA is proposed, in order to contribute to the correct waste management of future PLA wastes. 


\section{MECHANICAL RECYCLING}

Mechanical recycling represents one of the most successful processes and has received considerable attention due to its main advantages, since it is relatively simple, requires low investment, and its technological parameters are controlled [20].

The assessment of the degradation mechanism is necessary to determine the quality of recycled polymers and guarantee their further performance in second-market applications. The quality of recycled polymers has been defined as the combination between the degree of mixing, the degree of degradation and the presence of low molecular weight compounds[21]. It is known that polymers are subjected to the influence of degrading agents such as oxygen, light, mechanical stresses, temperature and water, which, separately or in combination, during its material loop (synthesis processing - service life - discarding - recovery), results in chemical and physical changes that alter their stabilization mechanisms and long-term properties[21]. The degradation makes physical properties and functional quality of a polymer worse, hence reprocessed products of high confidence are difficult to obtain. In particular, top quality is crucial in the case of thin films, for which optical and barrier properties, among other issues, play an important role [22]. These degradation processes may modify the structure and composition of the polymers and consequently change the thermal, viscoelastic and mechanical performance of the recyclates[21].

It is therefore necessary to implement experimental protocols to simulate the environmental conditions that plastics are subjected to during mechanical recycling. A multi-level scheme in which the different stages of assessment of mechanical recycling performed in lab-scale facilities are represented is shown in Figure 1, along with the analytical techniques commonly used to test the performance and/or degradation state of the resulting material. 


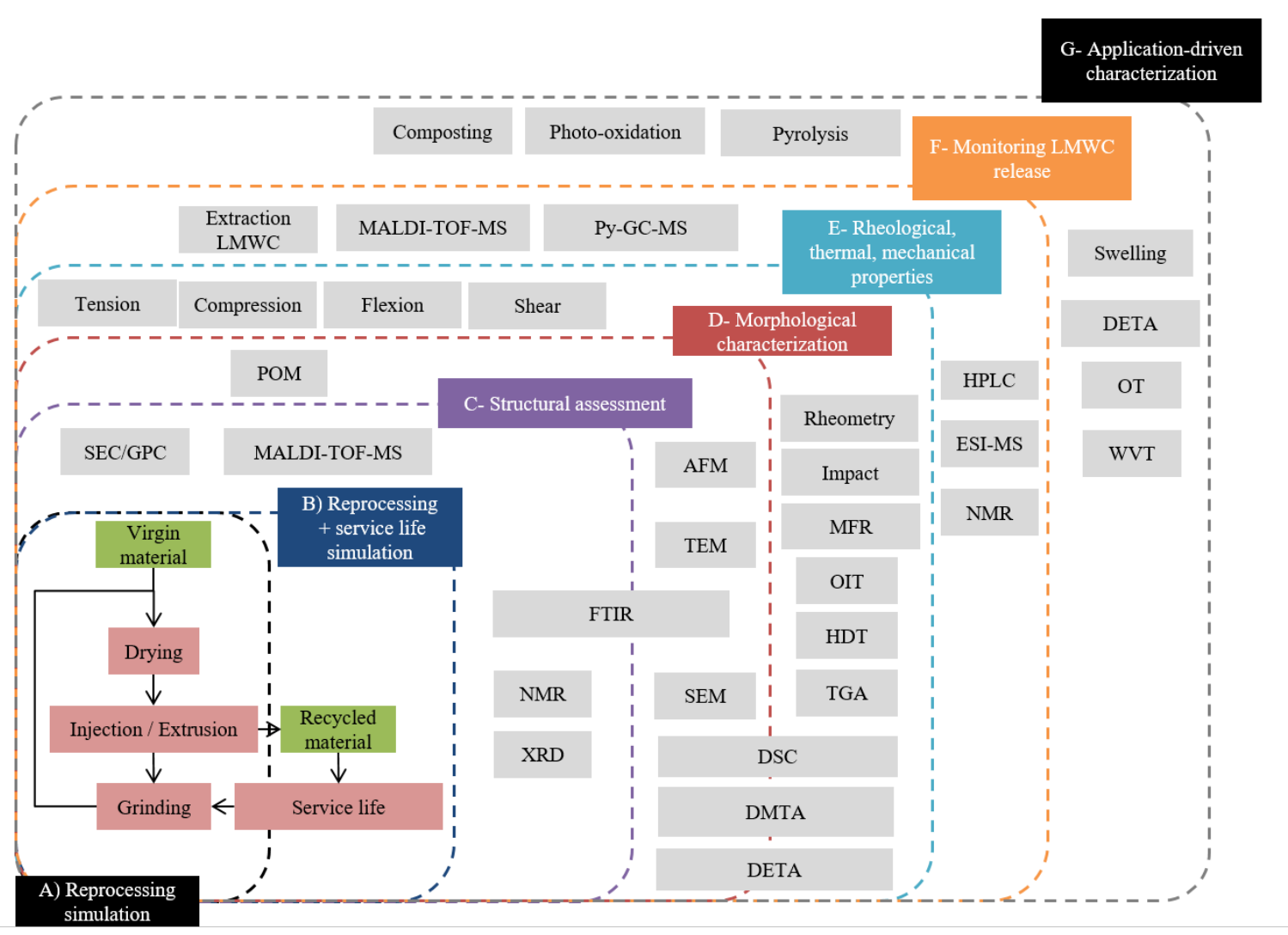

Figure 1. Multi-level characterization of recycled polymers. Levels are labelled from A to $G$ as indicated in the text.

The main steps of characterization are summarized in the following paragraphs.

\subsection{Simulation of recycling and service life}

Levels A and B represent the simulation steps for mechanical recycling and service life simulation, respectively, which account for not only the recirculation of industrial scrap into the processing step - commonly injection or extrusion-, but also for the application of a service life simulation before redirecting it to the processing step, in order to approach real process-use-discard pathways. All recycling studies take into account the Level A, but very few apply the Level B [23], probably due to the long required testing time. In this level, the drying step represents a critical point for ascertaining a significant quality level, since most of the recycled polymers are highly liable to humidity [24]-[27] . 


\subsection{Structural and morphological assessment}

Levels C and D account for the structural and morphological assessment of the chemical nature of polymer constituents after recycling. Techniques such as Size-Exclusion Chomatography (SEC), Matrix-Assisted Laser Desorption-Ionization Time-of-Flight Mass Spectrometry (MALDI-TOF-MS)[28]-[30], Nuclear Magnetic Resonance (NMR)[31], or Raman and Fourier-Transfrom InfraRed Spectrometry (FT-IR) are used[32]. The determination of the molar-mass distribution and the chemical nature of the polymer chains and/or their chemical groups along the recycling procedure permits monitoring the structural changes. In addition, Differential Scanning Calorimetry (DSC) is used to analyze kinetics of crystallization[33] and to determine the balance between crystalline, mobile, and rigid amorphous fractions in recyclates[34], which clearly modify their performance in second-life applications. As well, Dynamical-Mechanical Thermal Analysis (DMTA)[35]-[37] and Dynamic-Dielectrical Thermal Analysis (DETA)[38], [39] are of great importance to test the dynamic fragility of recyclates, according to the internal chain rearrangements.

\subsection{Feasibility of production and stability}

Despite the importance of Levels $\mathrm{C}$ and $\mathrm{D}$, common reports directly apply macroscopic studies (Level E) in terms of rheological, thermal and mechanical performance of recyclates, aiming at ensuring the feasibility of obtaining and their further performance in use. Only for high-tech added-value second-life applications, a thorough understanding of the reasons underlying the decay of desired properties would probably justify from a business point of view the investment in knowing the degradation mechanisms. Thus, the study of the rheological properties in order to assure proper flow during processing, as well as the mechanical characterization of the stress and strain at break or impact to check the resistance of second-life applications is fundamental. As well, the study of thermal properties such as the Oxidation Induction Time (OIT)[40], the Temperature of Oxidation (Tox)[41], the thermal and thermo-oxidative decomposition temperatures[42], the melting temperatures or the Heat-Deflection Temperature (HDT) are of immediate application and use in industrial quality labs. 


\subsection{Interaction of LMWC with environment}

Level F considers the extraction and analysis of the Low Molecular Weight Compounds (LMWC), which should be specially focused in specific sectors where the use of recyclates could be appointed, for their interaction with humans, food and or environment. Different extraction techniques coupled with chromatographic and spectrometric techniques are widely used at lab-scale[28], [43].

\subsection{Application-driven characterization}

Finally, the application of different characterizations is gathered in level G to stablish the quality of recyclates for a specific application, i.e. aiming durability. Techniques for the analysis of mass-transport properties for the use of recyclates as packaging[44] or concerning dielectric properties [39], [45], [46] are used, among others. On the other side, when the application is to find the most sustainable discarding process for wastes, the combination of further simulations of waste management options [13] such as composting[47], [48] or energetic valorization[20], [42], [49]-[51], among others, have been reported. 


\section{IMPACT OF MECHANICAL RECYCLING ON PLA PERFORMANCE}

Simulation of mechanical recycling by multiple processing and service life by accelerated thermal ageing to assess the effects of thermal and thermo-mechanical degradation has been previously performed for commodities [31], [34], [41], [52]-[57] such as polyethylene PE [53], polypropylene PP [53], polystyrene PS [54], [55], poly (vinyl chloride) (PVC) [57] or poly(ethylene terephthalate) PET [29], [34], [41], [56], [58], [59], among others. Mechanical recycling of biopolymers has been mainly reported for poly(hydroxybutirate) [60], poly(caprolactone)[61] and polylactide. The mechanical recycling of polylactide has been approached in lab-scale studies by means of multiple injection [35], [62] and extrusion[44], [63], [64] steps, during one [65], three [64], five , [66] and ten [63] processing cycles, and the recyclates characterized in terms of structural and morphological analysis[35], [62], [65], rheological, thermal and mechanical properties [35], [62], [63], [65], [66] release of LMWC[30] , and application-driven techniques such as mass-transport [63] or dielectrical properties[38]. The mechanical recycling of blends with commodities such as polycarbonate or HDPE, or biopolymers such as thermoplastic starch has been also studied [67]-[69]. Likewise, the differences of recycling PLA and PLA plasticized with PEG have been evaluated [66]. As well, the combination with other waste management techniques, such as energetic and biological methods, is of interest in literature [26], [49], [50].

In the following sections, the effects of mechanical recycling at the different levels of analysis are gathered, compared and discussed, in order to offer a general overview of the influence of thermo-mechanical degradation on the performance of PLA recyclates.

\subsection{Structural changes}

Analysis of PLA species appeared after multiple injections, as analyzed by MALDI-TOFMS [30] followed the postulated mechanistic routes of polyesters which are: 
(i) hydrolysis, which leads to the formation of hydroxyl and carboxyl linear oligomers with shorter chain length; (ii) esterification; (iii) intramolecular transesterification, both by backbiting, i.e., from the end of the chain, and at the middle of the chain, which leads to the formation of cyclic oligomers and linear species with shorter length; (iv) intermolecular transesterifications, which interchange ester units between different chains, leading to an increase in the heterogeneity of the polymer; and (v) acyl-O and alkyl-O $\beta$-C initiated homolytic chain scissions at temperatures above melting, as well as radical reactions induced by oxygen, which may produce random chain cleavage, leading to the formation of mainly linear hydroxyl and carboxyl terminated species. The proposed degradation routes and interacting species are shown in Figure 2. The apparition of these new carbonyl-linked species both in the middle and at the end as carboxyl groups species was also qualitatively measured by FT-IR experiments [35].

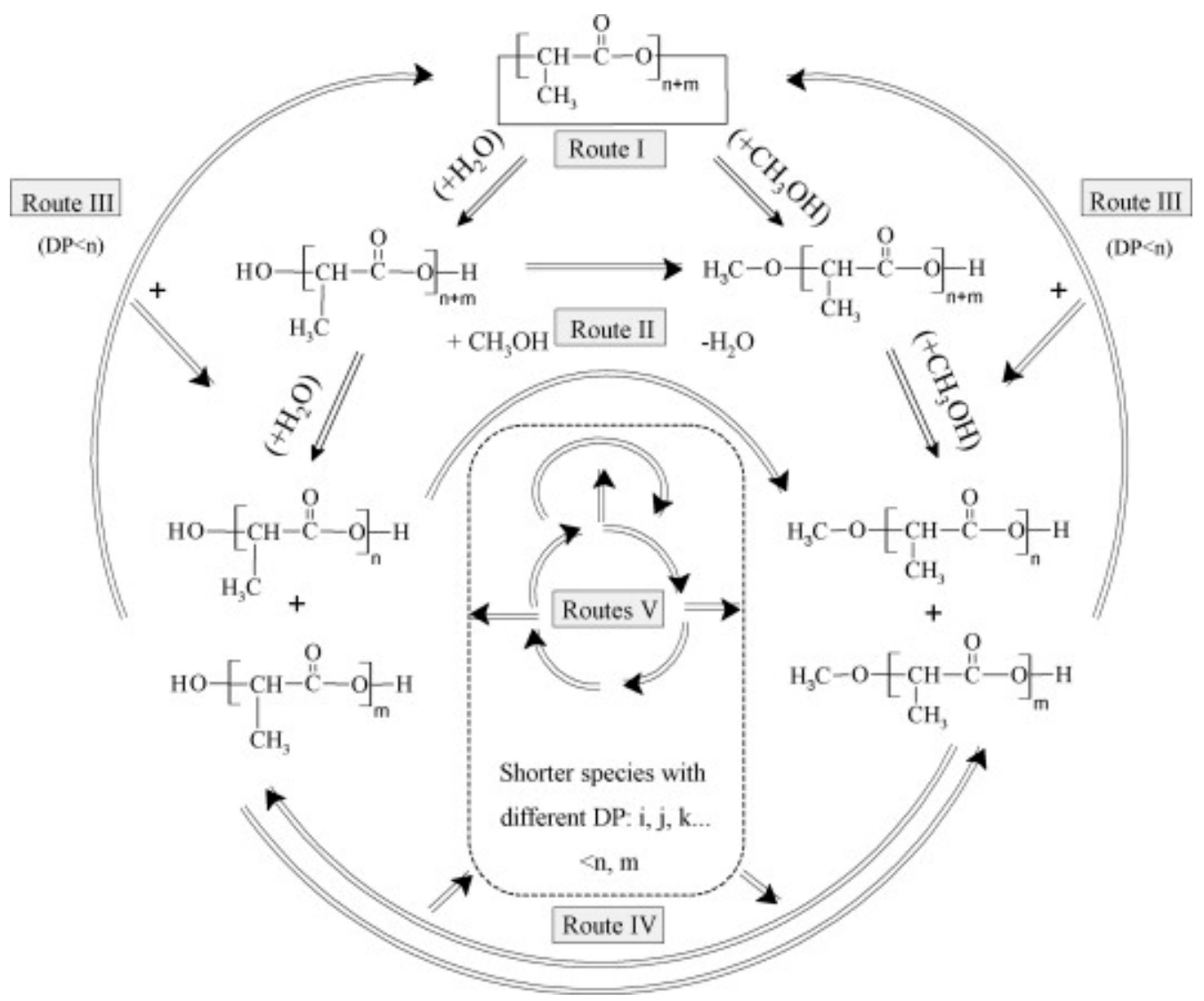

Figure 2. Degradation pathways proposed for recycled PLA. Reprinted from [30], with permission from Elsevier. 
In general terms, all reported studies showed that processing of PLA was responsible for a decrease in molar mass, as determined by SEC/GPC for different PLA grades, due to chain scission [35], [64], [65], [70], as shown in Figure 3 for the cases of one injection process [65], combined extrusion and injection [65] , three successive extrusions [64], five [35] and seven [62] successive injections, in terms of number-average molar mass $M_{n}$ and viscous molar mass $M_{V}$. It should be pointed out that relatively small changes in molar mass might suggest the possibility of high number of available recycling steps. However, other indicators of degradation concerning the morphological properties and the performance of recyclates should be argued before making a decision, as shown in next sections.

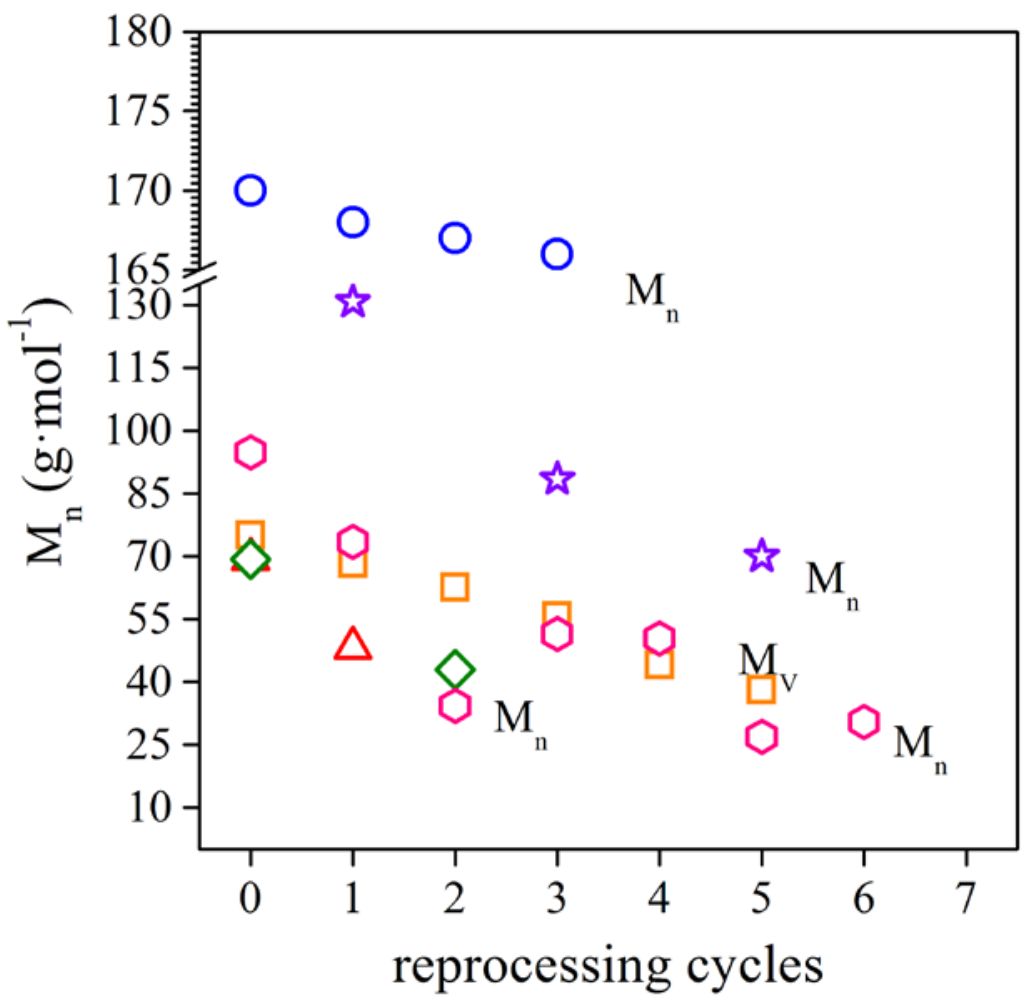

Figure 3. Molar mass decay of PLA after one injection process (triangles[65]), combined extrusion and injection (diamonds [65] ), three (circles [64]) and five (stars [66]) successive extrusions and five (squares [35]) and seven (hexagons[62]) successive injections, in terms of number-average molar mass $M_{n}$ and viscous molar mass $M_{V}$.

\subsection{Morphological characterization}


The reported studies on the topography of reprocessed PLA generally show pictures obtained by Scanning Electron Microscopy (SEM) [35]. The SEM pictures for virgin PLA and PLA reprocessed via injection molding five times are shown in Figure 4. Images were taken on the surface of dog-bone probes. The micrographs of RPLA-5 presented a loss of the orientation of the processing lines shown by VPLA. In addition, the surface seemed to be less smooth and more liable to mechanical scratches. The morphological defects may arise as a result of new structural and conformational arrangements of PLA.
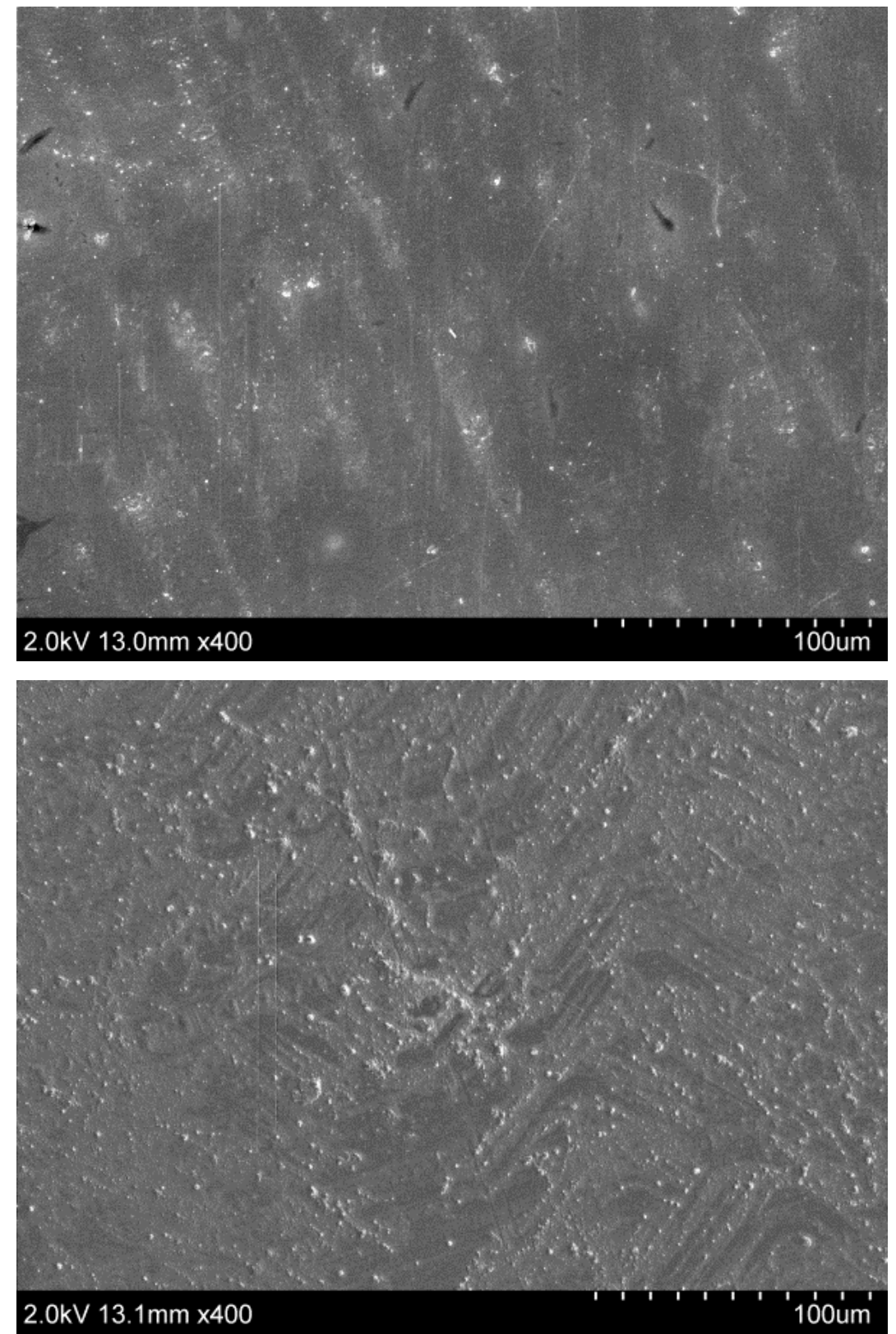

Figure 4. SEM pictures of virgin (up) and reprocessed (down) polylactide (400X) 
The effect of the chain scission induced by thermo-mechanical degradation can be monitored by techniques such as Differential Scanning Calorimetry, in terms of the amorphous-to-crystalline ratio, and the different thermal transitions which offer a great amount of information. An example of the second heating scan of a PLA reprocessed up to five times by successive injection molding cycles is shown in Figure 5. [35].

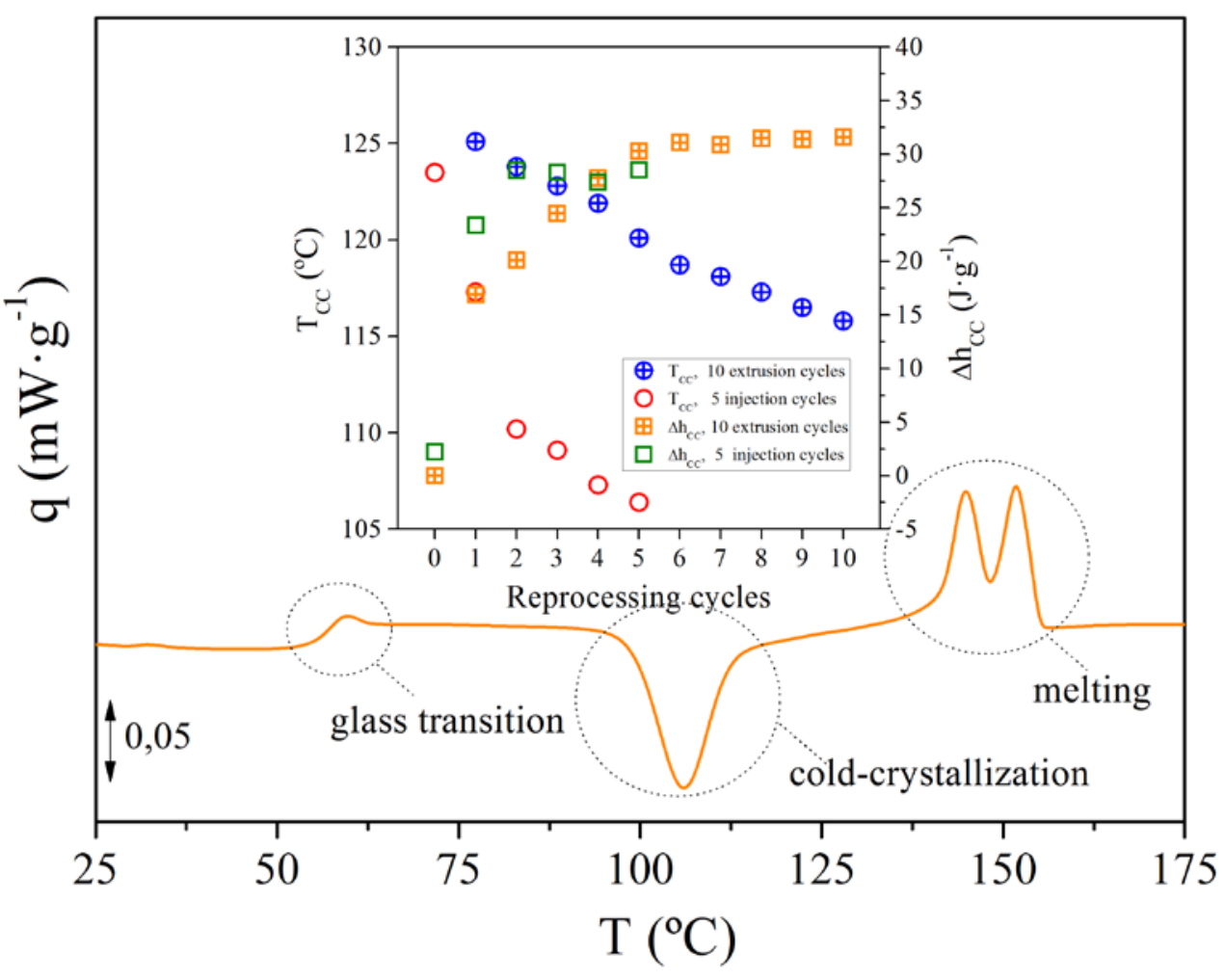

Figure 5. DSC trace of second heating scan for PLA reprocessed five times. Inset: Evolution of coldcrystallization temperatures $\boldsymbol{T}_{C C}$ and specific enthalpies $\triangle \boldsymbol{h}_{C C}$ for PLA reprocessed by means of five injection moulding [35] cycles and 10 extrusion cycles [63].

The study of several thermal events such as the glass transition $\left(\sim 50-70{ }^{\circ} \mathrm{C}\right)$, coldcrystallization $\left(\sim 95-125{ }^{\circ} \mathrm{C}\right)$ and bimodal melting $\left(\sim 135-160{ }^{\circ} \mathrm{C}\right)$ permits monitoring chain scission in a cost-effective way. Different observations can be highlighted: 
(i) The enantiomeric distribution of D-PLA and L-PLA can affect the amorphous-tocrystalline ratio. Indeed, PLA with low D-content ( $<0,5 \%)$ may show a fully amorphous morphology after several reprocessing steps [35], [63], being corroborated [35] by FT-IR studies by looking at the bands at 687, 739, 921 and $1293 \mathrm{~cm}^{-1}$, representative of crystalline regions [71], which did not appear along the reprocessing cycles. In this case, the glass transition temperature $\mathrm{Tg}$ did not practically changed. In contrast, a PLA with a $8 \%$ of D-content showed the apparition of a crystalline phase of $\sim 38 \%$ and $~ 53 \%$ after the second and seventh reprocessing steps, respectively [62], having an impact on mechanical properties, and on the $\mathrm{Tg}$, which was dropped by $\sim 10^{\circ} \mathrm{C}$. Thus, the proportion of L/D ratio can affect the possibility of the presence of a crystalline phase after a certain number of processing cycles that might affect the performance of PLA because of decoupling of amorphous and crystalline phases, decreasing chain mobility and modification of the mechanical properties with further processing [35], [62].

(ii) Though being amorphous PLA, the study of the cold-crystallization and melting phenomena is of extreme importance. The cold-crystallization temperatures $T_{C C}$ and specific enthalpies $\Delta h_{C C}$ are particular indicators of degradation, which respective reductions and increases pointed out the existence of chain scission processes, as shown in Figure 5 [35], [63][66]. The chain scission due to thermo-mechanical degradation may lead to shorter chains acting as nucleation centers, thus increasing the $\Delta h_{C C}$ and then modifying the crystallization kinetics and consequently affecting to the processability of PLA [72].

(iii) The characterization of the melting behavior of the newly formed crystallites during cold-crystallization is also suitable to monitor thermo-mechanical degradation. The shape of the endotherms of PLA can show a change from an uni-modal to a bimodal distribution, which might be attributed to a superimposed melting-crystallization-melting process, dependent on the kinetics of the temperature program [73]-[75]. The combination of a deconvolution procedure [76] and a partial areas study [41] showed that the effect of the thermo-mechanical degradation could be ascribed to the variation of the area of the first melting area, which would be indicative of the promoted tendency of crystals to melt, and thus for molten shorter chains to recrystallize [35]. 
All the aforementioned indicators of degradation indicated a sort of threshold for recycling PLA at the second reprocessing step [35], due to the influence of the morphological variations on the performance of recyclates.

\subsection{Rheological, thermal and mechanical properties}

The effect of 5 injection cycles [35] and 10 successive extrusion cycles [63] on the mechanical properties of polylactide, as determined by tension and Charpy impact tests, is shown in Figure 6.. A first observation at the tensile stress-strain curve shows that after 5 reprocessing cycles, the slope of the curve, i.e. the Young modulus was not significantly modified. As well, the strain at break was pretty similar to that given by the virgin PLA. As well, stress parameters such as tensile stress and stress at break also showed small variations after several reprocessing cycles. These indicators thus did not show any remarkable variation and could therefore lead to misleading discussions if other parameters were not monitored. Indeed, the evolution of the impact properties as a function of the variation of the melt mass-flow rate (MFR) is shown, in order to connect rheological properties with mechanical performance. The MFR was slightly modified among the first recyclates, but the difference between successive extrusion cycles was higher, the more the number of cycles was applied, due to the increase of scissored chains and the subsequent augment of flowability. In line to the MFR variation, recycling usually affects drastically to the macroscopic mechanical properties, as shown for the decrease of the impact resistance. 

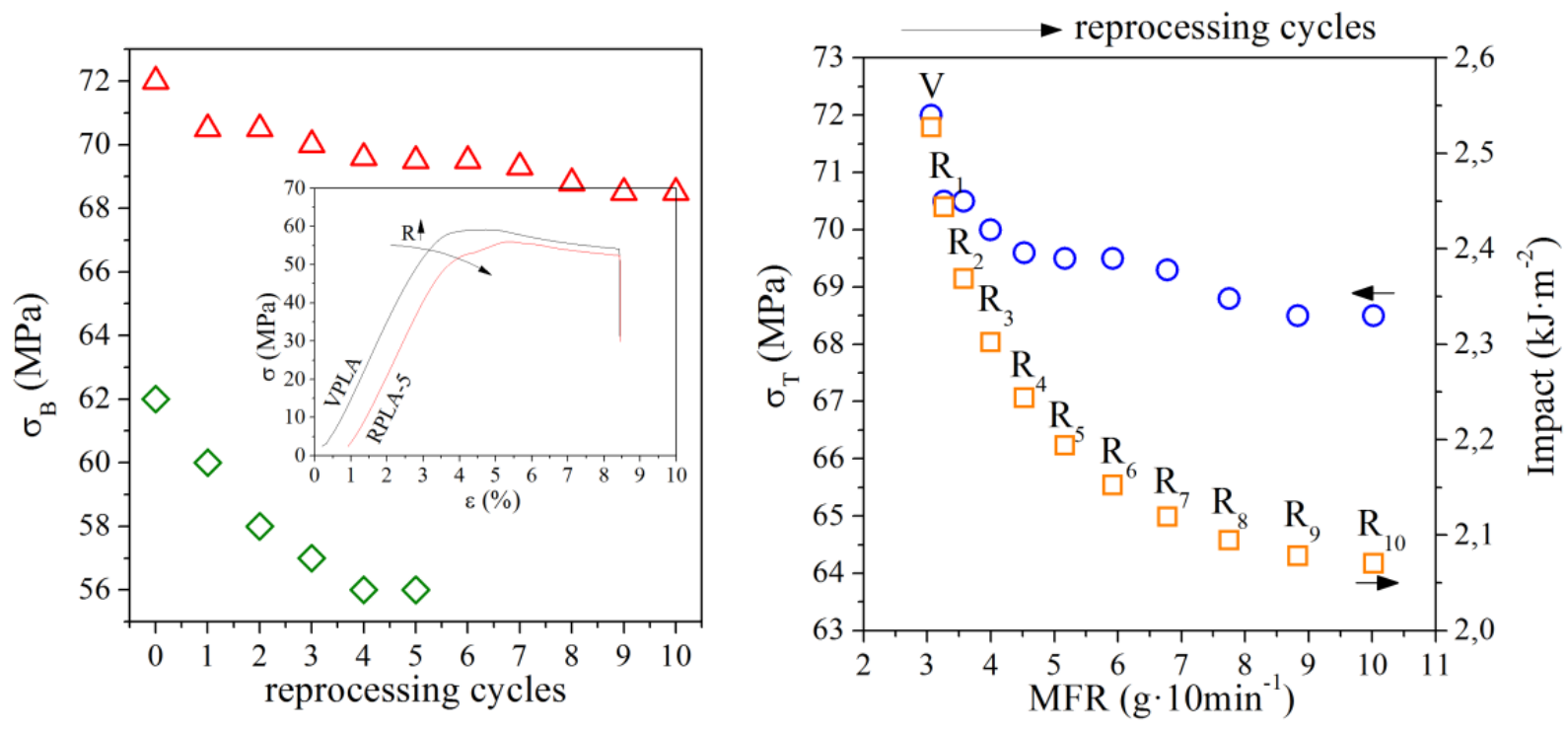

Figure 6. Influence of reprocessing on the mechanical properties of polylactide submitted to five injection cycles [35] and ten extrusion cycles [63]; (left) evolution of stress at break / inset: example of tensile stressstrain curves for virgin (VPLA) and PLA reprocessed five times (RPLA5); (right) relationship between the melt mass-flow rate with tensile testing and energy of impact [63].

Concerning thermal properties, the influence of successive reprocessing by different reported studies, i.e. (i) injection and extrusion followed by injection [65], [77] , five successive injections [35], [49], [50] and ten extrusions [63], on the glass transition and melting temperatures, as obtained by DSC, and the thermal and thermo-oxidative decomposition temperatures, as obtained by TGA, is shown in Figure 7. Several observations can be pointed out: 


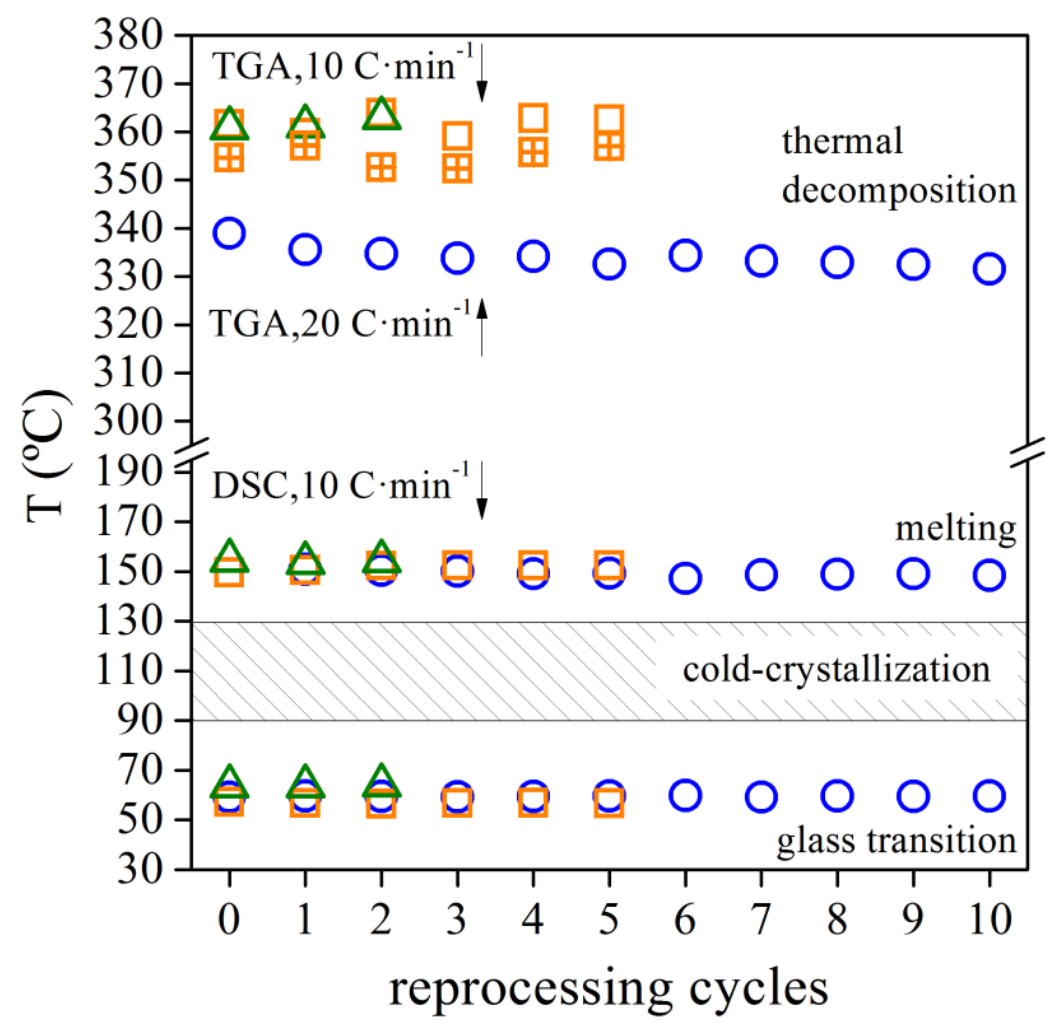

Figure 7. Temperature windows of PLA reprocessed up to 2 (extrusion + injection, triangles)[65], [77] , 5 (injection, squares)[35], [49], [50] and 10 (extrusion, circles)[63]. Cold crystallization is shown in Figure 3.

(i) The glass transition temperature $\mathrm{Tg}$ of PLA was not influenced by reprocessing, since its variation lay in a $3{ }^{\circ} \mathrm{C}$ range, regardless the molar mass reduction suffered by the polymer. As well, the melting point $T_{M}$ was scarcely diminished, thus the window of processing temperatures of virgin PLA can be adapted for further recyclates. Concerning thermal treatments, the cold-crystallization $T_{C C}$ should be taken into account, as shown in Figure 7, which can be decreased down to $10^{\circ} \mathrm{C}$ from the initial values, due to the liability of recyclates to nucleate crystalline domains at lower temperatures, as a consequence of the presence of shorter chains due to thermo-mechanical degradation. 
(ii) Concerning the thermal decomposition, it happened at temperatures above $300{ }^{\circ} \mathrm{C}$, but special care has to be taken when comparing reported values. In fact, one should think after considering Figure 7 that the thermo-oxidative decomposition starts at higher temperatures than the thermal decomposition of PLA, which is obviously not true, since the decomposition temperature is reduced with the presence of $\mathrm{O}_{2}$. Indeed, the apparition of new sites liable to $\mathrm{O}_{2}$ in the PLA structure may promote faster decomposition at lower temperatures at high reprocessing cycles, which may need lower temperatures to start their decompositions [50]. In order to prevent the results from the dependence of the experimental conditions of the thermogravimetric analysis, a novel methodology was proposed in literature [42] and applied for mechanically reprocessed PLA[49], [50]. In short, from the application of multi-rate linear non-isothermal thermogravimetric experiments at different heating rates, the evolution of the decomposition temperatures could be fitted to the TDB model and the Zero-Decomposition Temperatures (ZDT) calculated for comparison among recyclates, where "zero" stands for the theoretical application of a heating rate close to 0 .

Combined thermal and mechanical characterizations have been also applied to test the influence of reprocessing on reprocessed polylactides. Such is the case of the studies of dynamic fragility reported for PLA subjected to five successive injections, which results are shown in Figure 8, in terms of loss tangent. After 5 reprocessing cycles, the relaxations corresponding to over-Tg phenomena, such as the cold-crystallization, were not relevant, being the glass-rubber relaxation uni-modal. As well, although the width of the relaxation and the temperature of the $\operatorname{tg}(\delta)$ maxima remained almost unaltered, a deep study of the frequency-dependence of the relaxation offered more information. Actually, the application of the Vogel-Fulcher-Tamann-Hesse model[35] permitted the calculation of the dynamic fragility parameter $\mathrm{D}$, which decreased after the second reprocessing step, as shown in the inset of Figure 8. This in turn provoked an increase in free volume which could affect the permeability of gases. In fact, the evolution of the permeation coefficients of oxygen and water of PLA reprocessed up to 10 times [63] shown in Figure 9, points out a sort of step after the second reprocessing cycle, in which the increment of permeability was significant. 
J.D. Badia, A. Ribes-Greus. Mechanical recycling of polylactide, upgrading trends and combination of valorisation techniques. European Polymer Journal, 2016; 84:22-39

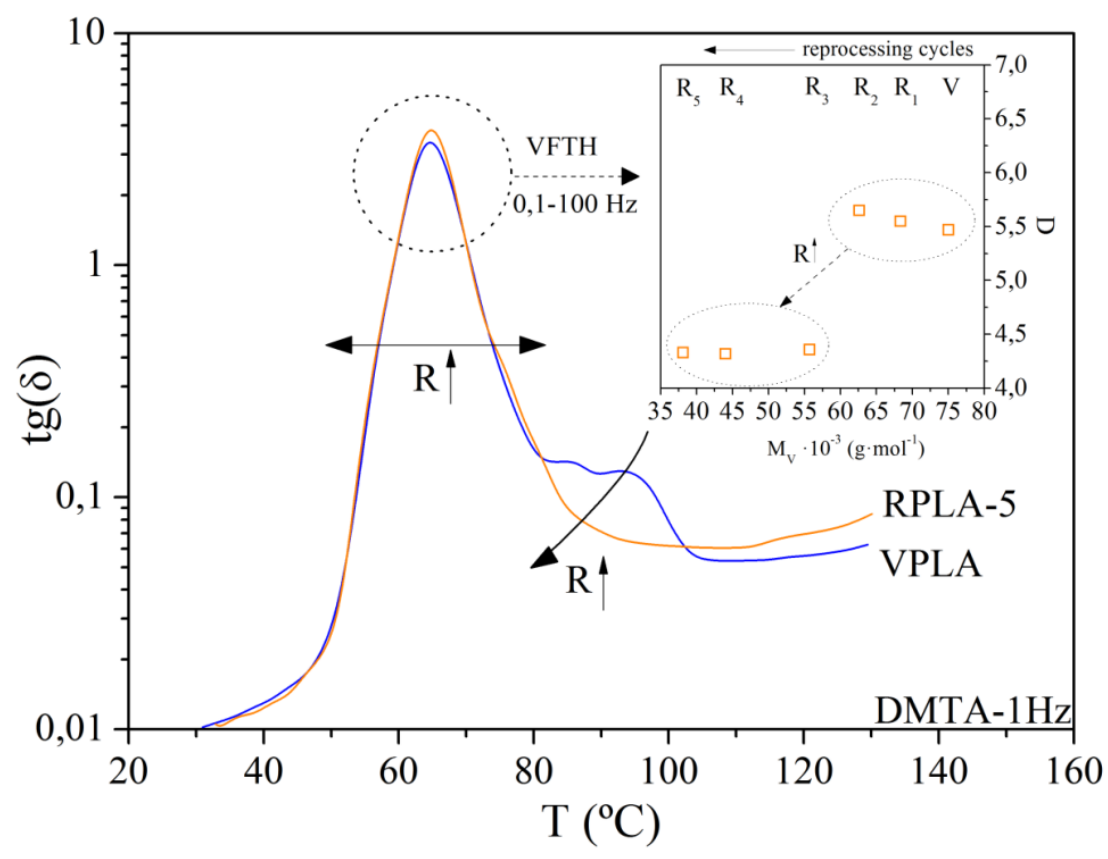

Figure 8. DMTA spectra of the loss tangent obtained at 1Hz for virgin PLA and PLA reprocessed by means of five successive injection cycles. Inset: evolution of the dynamic fragility parameter $D$, as obtained by VolgerFulcher-Tamman-Hesse model, as a function of viscous molar mass[35].

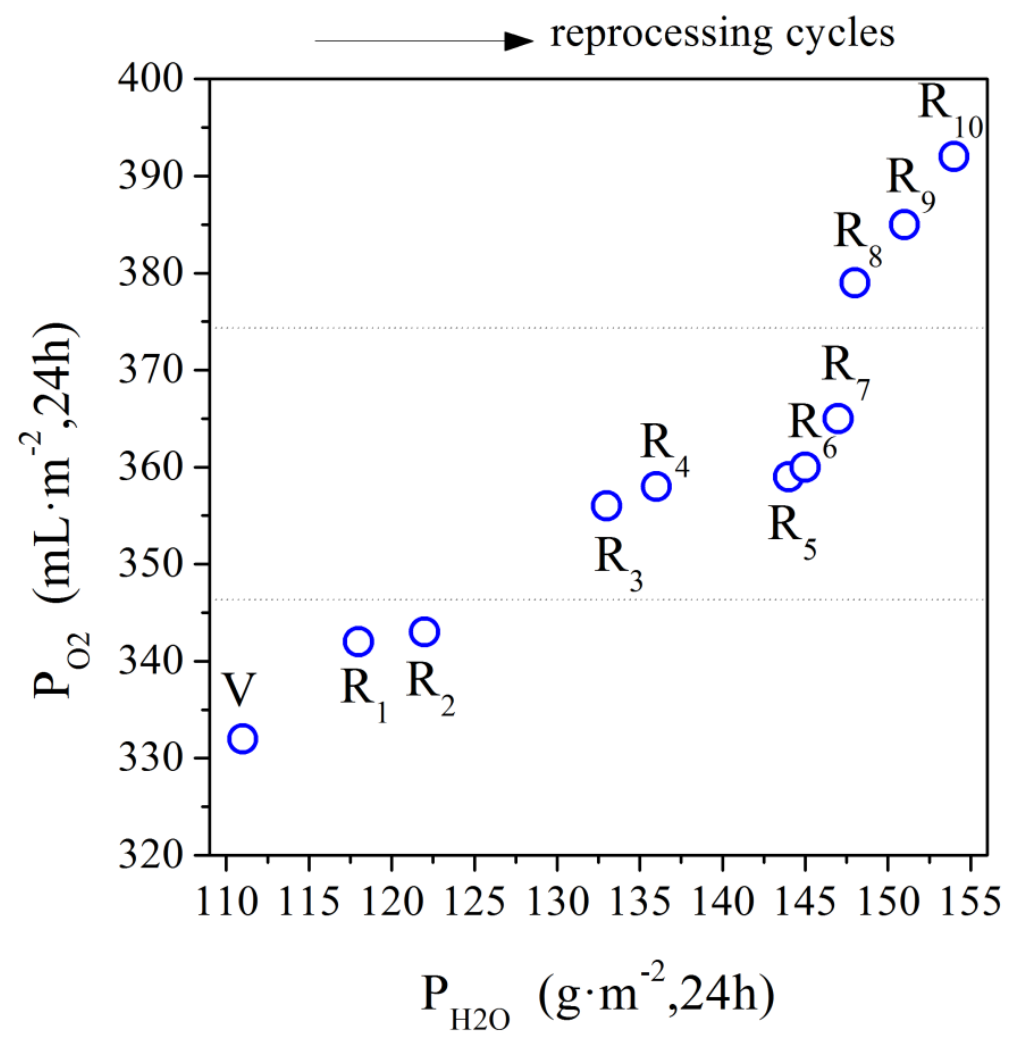

Figure 9. Evolution of permeation parameters of PLA reprocessed up to 10 times, for oxygen and water [63] 


\subsection{Release of low molecular weight compounds (LMWC)}

The use of MALDI is highly indicated for the elucidation of oligomeric species from biopolymers [78]. It is reported that multiple reprocessing affects the oligomeric distribution of PLA; thermo-mechanical degradation seemed to occur mainly via hydrolytic, homolytic and intermolecular transesterifications, giving rise to a noticeable major abundance of $\mathrm{H}-\left[\mathrm{LA}_{\mathrm{L}}\right]_{\mathrm{n}}-\mathrm{O}-\mathrm{CH}_{3}$, where LA stands for lactic acid repeating units, as shown in Figure 2. As well, thermo-oxidative ageing at $60{ }^{\circ} \mathrm{C}$ during 12 weeks promoted intramolecular transesterification and chain-scission, mainly by depolymerization of cyclic species. Thus, the oligomeric species susceptible of further degradation and release to the environment are cyclic $\left[\mathrm{LA}_{\mathrm{C}}\right]_{\mathrm{n}}$ and linear $\mathrm{H}-\left[\mathrm{LA}_{\mathrm{L}}\right]_{\mathrm{n}}-\mathrm{O}-\mathrm{CH}_{3}$ and $\mathrm{H}-\left[\mathrm{LA} \mathrm{A}_{\mathrm{n}}-\mathrm{OH}[30]\right.$. $\mathrm{H}_{2} \mathrm{O}, \mathrm{O}_{2}$, temperature, and their combinations are the main factors to be taken into account. Degradation by $\mathrm{H}_{2} \mathrm{O}$ moieties lead to the formation of lactic acid and its oligomers terminated by hydroxyl and carboxyl end groups, as determined by ESI-MS to reprocessed PLA subjected to hydrolytic conditions [64]. Temperature is the main degrading factor leading to the formation of LMWC from PLA. Prior studies by pyrolysis-GC/MS have revealed that, at temperatures below $230^{\circ} \mathrm{C}$, the polymer backbone cleavage is mainly caused by non-radical intramolecular transesterification, leading to the formation of cyclic oligomers, acetaldehyde, ketene, and carbon monoxide units as by-products [79], [80]. Above $270^{\circ} \mathrm{C}$, the use of by pyrolysis-GC/MS showed the occurrence of cis-elimination and radical reactions which promote further evolvement of species such as acrylic acid, carbon dioxide or methylketene [81]. Since the temperature of many PLA processing routes does not exceed $230^{\circ} \mathrm{C}$, it is accepted that thermal degradation occurs via non-radical reactions, leading to significant decrease in molar mass which has an important effect on the crystallization rate, morphology and final performance of PLA [82]. 


\section{UPGRADING RECYCLED PLA}

In order to confer recycled PLA with improved properties, different thermal and chemical treatments have been applied. As well, recycled PLA has been introduced in some formulations for novel blends and composites, as schematized in Figure 10.

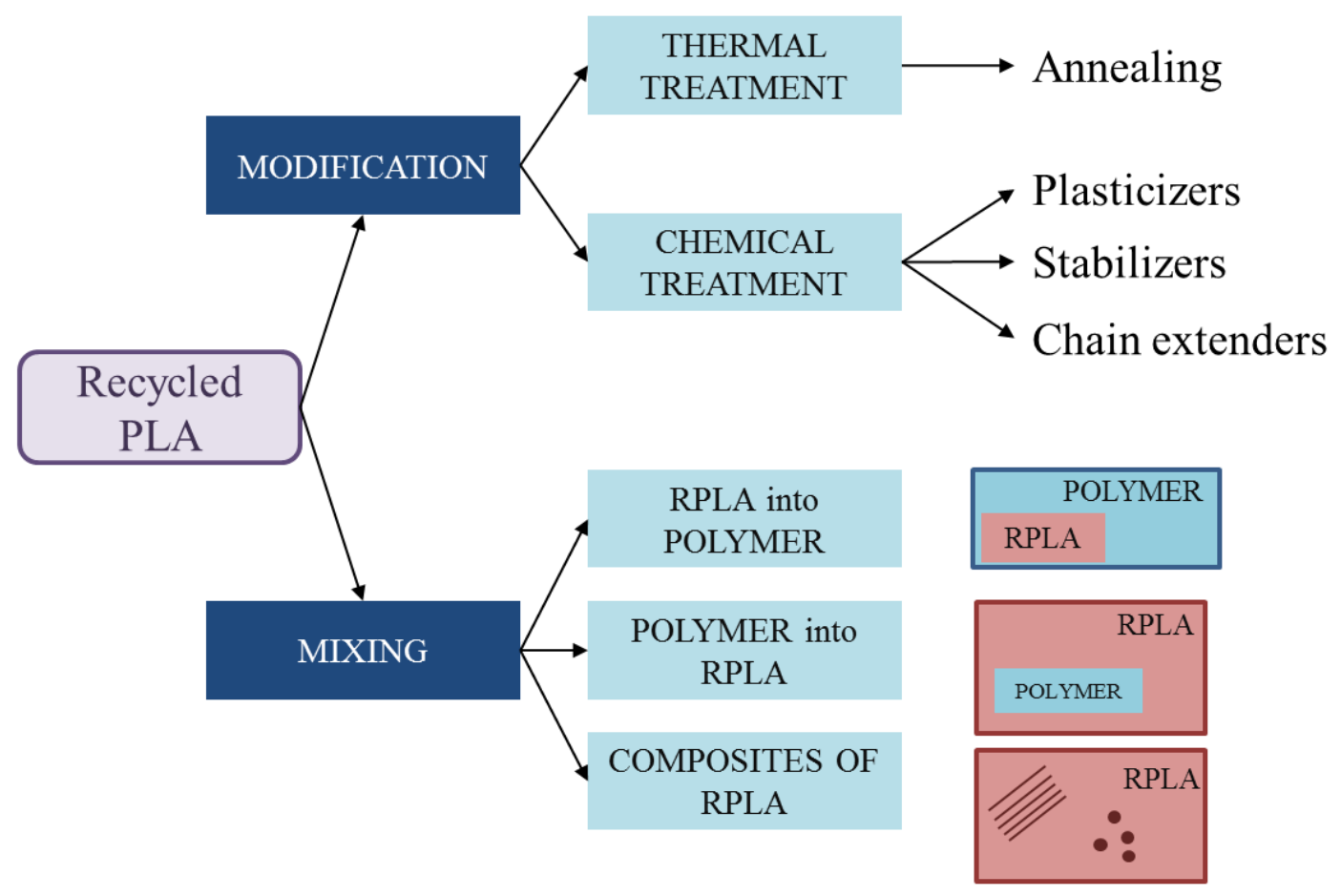

Figure 10. Summary of upgrading strategies reviewed in this paper 


\subsection{Thermal treatments. Annealing of recycled PLA. Influence on mechanical properties}

The use of temperature to modify PLA has to be carefully addressed. L. Santonja-Blasco et al showed the impact of high temperatures at short times on the kinetics of the associated decrease of molecular weight [82]. As shown in Figure 7, PLA can be processed between $\sim 75^{\circ} \mathrm{C}$ and $\sim 135^{\circ} \mathrm{C}$ as a viscous liquid and modify its amorphous-tocrystalline ratio choosing appropriated temperatures. In this line, Carrasco et al subjected PLA, previously extruded and injected during one cycle, to thermal annealing at $120{ }^{\circ} \mathrm{C}$ during $6 \mathrm{~h}$ to induce an increase of crystallinity [65], [77] which had been lost during the processing operations. This correlated with the increase of mechanical properties such as young modulus, and yield strength, with the counterpart of the decrease of the elongation at break. As well, the fracture toughness was analyzed considering low and fast impact rates. Indeed, at low testing rates, fracture toughness increased after annealing whereas at impact rate, the annealing treatment caused a slight decrease on the $K_{I C}$ values, which was supported by fractographic analysis.

\subsection{Chemical treatments. Influence of plasticizers, stabilizers and chain extenders}

The use of plasticizers to improve the processability and versatility of performance of PLA is of relevant importance and therefore the mechanism of degradation of these blends during mechanical recycling were investigated by Brüster et al [66]. Multiple reprocessing of a plasticized PLA grade obtained by grafting/polymerizing acryl-PEG within PLA via reactive extrusion was assessed within a multiscale approach. Thorough structural analyses revealed that reprocessing caused these mechanisms: chain scission of PLA, crystallization of PLA, damaging of inclusions, and decrease of the size of poly(acryl-PEG) phases within the inclusions, thus causing embrittlement, reducing the potential of reusing PLA at the same application. 
In order to prevent the problem of degradation during reprocessing, the incorporation of specific additives can minimize degradation. Known antioxidants are thus indispensable additives added during compounding and pelletizing processes that act by neutralizing the radicals and preventing degradation. Properties such as impact resistance, flowability or UV-protection [83] can be improved through proper additives but this may incur an extra payment to be studied in each case to achieve the optimal ratio between properties and cost. For example, the intermolecular transesterification occurring during the melt [84], [85] of PLA could be minimized by stabilizers such as 1-4 dianthraquinone [80] or benzoyl peroxide [86]. Extended studies [62] showed the influence of tropolone, pbenzoquinone and hydroquinone which were blended with PLA in a mixer at $200{ }^{\circ} \mathrm{C}$ under air, and the properties were measured after $10 \mathrm{~min}, 20 \mathrm{~min}, 30 \mathrm{~min}$ and $40 \mathrm{~min}$ of mixing time. The tropolone acted as catalyst stabilizers and quinine as oxidative stabilizers. It was shown that properties such as glass transition temperature, Young modulus, stress and strain at break or zero viscosity, among other, were effectively stabilized, especially after the addition of quinones. In particular, the crystallization upon cooling was suppressed and the molar mass of PLA maintained at good levels. The quinones were found to be efficient stabilizers to trap free radicals and maintain PLA chain length at the processing temperatures. 
The use of chain extenders and branching agents by reactive extrusion should also be considered[87]-[90]. It has been reported for PLA and different blends, and could also be extended to preventing or healing chain scission during reprocessing. Such is the case of chain extenders like glycidil methacrylate which increase mechanical, thermal and rheological properties due to stabilization of molar-mass by phase dispersion[91]. Other options reported for recycled PET based on caprolactam or trimellitic anhydride could be investigated[92]. Additives such as Irganox and Irgafox stabilize the molar mass reduction induced by thermos-mechanical degradation[93]. Even more, a study reported the use of these additives for the thermal stabilization of PLA after four subsequent extrusion cycles [94]. The results showed that the synergetic effect of primary and secondary antioxidants was a suitable way to thermostabilize the PLA. However, the stabilizing effect was suppressed by the presence of non-radical reactions that occurred during the exposition of PLA to higher temperatures and shear. Also the use of phosphites has been shown that can react with PLA[95], [96] molecules to increase the molar mass, complex viscosity and storage modulus, so the compounds take effective chain extensions in the melt processing of recycled PLA.

The use of nanoclay organic modifiers could also be considered since they prevent from thermal oxidation, even though this option may affect to crystallinity and thus affect to other physic-chemical properties[97]. As well, the addition of zeolites[98] with a PEG stabilizer, graphene functionalized epoxies[99] or complexes with ciclodextrin [100], among other options, could be interesting to investigate in reprocessing studies. 


\subsection{Incorporation of polymers into recycled PLA}

The incorporation of polymers into recycled PLA or into virgin PLA has to be addressed in terms of compatibility and miscibility [101]. One of the main research lines to improve PLA properties is focused on PLA toughening by diverse routes such as plasticization, copolymerization, and melt blending with flexible polymers, as detailed in literature [102]. It was argued that reactive blending was more effective in improving the toughness of PLA blends, particularly the impact strength. In some cases, super-tough PLA blends were achieved with the addition of a large amount of non-biodegradable petroleum-based polymers, which compromised the integral biodegradability of the PLA. Even more, the improvement in impact toughness was usually accompanied by a decrease of strength and stiffness. As well, a focus on the not well understood yet influence of crystallization was raised.

Concerning the mechanical recycling on PLA modified with elastomeric polymers [103], the recyclability could not be warranted since the performance of recycled PLA blends by means of three successive injection cycles was affected by the change of crystallinity. This was correlated with a decrease of molar mass, due to chain scission occurred during reprocessing. As a consequence, the recycled materials were stiffer, with reduced deformability and impact resistance.

\subsection{Incorporation of recycled PLA into other polymer matrixes.}

Primary in-plant recycling is firstly advisable to optimize the investment in PLA to its higher extent. In this line, the processing equipment and parameters can be suited to process PLA sheets directly and economically into recycled PLA pellets, which can be added in $20-50 \%$ blend with virgin PLA [104] . In this line, a pilot project was started in PLA recycling by yogurt maker Stonyfield Farm, which began working with NatureWorks on mechanical recycling of PLA trim scrap from its thermoforming/filling/sealing packaging lines [105]. Other studies have pointed out the potential of internal recycling up to a recycling quota of 50\%, maintaining the mechanical and optical properties, with little influence on the molar mass [44]. 
Concerning post-consumed PLA, the possibility of finding PLA-based plastic residues into the current plastic streams in a near future has to be also considered, since PLA materials will replace plastics such as PE, PS or PET in household or packaging in a great extent. In particular, the separation technologies stand out as one of the critical steps for the identification and separation of commingled plastics. Such is the case of the use of chemometric strategies for the discrimination of PET and PLA by the use of hyperspectral imaging [106] or Near Infrared Technology. When these polymers appear in a plastic stream, both chemical and mechanical methods are taken into account. Shortly, the chemical methods rely on the different reactivity to solvolysis of PLA/PE , PLA/PBS [107] or PLA/PET [108] for selective depolymerization. Mechanical recovering by blending post-consumed plastics can be of high interest due to the synergy of performance that the different constituents can offer to the final product. Such was the case of PLA/PS blends obtained to both balance the cost effective production of PLA and enhance the degradability of PS packages [109], [110]. Furthermore, the interest was focused on the possibilities of re-using post-consumed PLA/PS 50/50 (wt\%) blends by the use of multiple processing through extrusion and injection[111]. In general terms, a reduction of the apparent viscosity of the blend with the reprocessing cycles, which was attributed to the reduction of the molar mass, was found to negatively affect the mechanical performance. Thus, instead of reprocessing PLA/PS blends as a whole, it was concluded that PLA/PS waste could be suitable just as an additive during the compounding of the raw polymers or the PLA/PS blends. 


\subsection{Compositing and its consequent recycling}

The use of fibers or particles to reinforced PLA is a common strategy followed to add value to the polymer in terms of performance and sustainability [112]-[116]. Biocomposites based on a biopolymer matrix and their recycling make possible to retain the whole carbon content and save primary resources, offering reductions in weight and therefore cost in applications such as automobiles, construction, packaging or furniture, among others, and give less dependence on petroleum-based resources [117]. Biocomposites prepared from recycled PLA with cellulose fibers has been reported, showing a diminution of mechanical properties such as elongation and stress at break and elastic modulus, for composites with a 50\% of loading of recycled PLA. In contrast, for loadings of $20 \%$, these properties were kept up to further 6 processing times [118], although the molar mass had been halved.

The use of natural fibers to improve the performance of PLA and to contribute on its sustainability[119] has been widely focused. However, the study of recyclability of reinforced PLA biocomposites is still a matter under study.

Generally, it is expected that biopolymer-reinforced composites have less recyclability than their neat thermoplastic matrix, because composites are more sensitive to thermomechanical degradation. Thus, recycling is usually guaranteed up to several reprocessing cycles until the mechanical properties are conserved and then are sent for composting.

Multiple processing may even enhance the interfacial adhesion between fillers and matrix, which results in a reported increase in thermal stability in the reprocessed biocomposites [119]. However, different degradative effects can happen because of successive recycling of biocomposites, such as fibre length reduction and chain scission in the matrix, which leads to a decrease in the molar mass and an increase in crystallinity. 
For instance, it was shown that PLA/cellulosic fibres composites could be successfully recycled up to 4-5 times without significant losses of tensile strength [120]. As well, the use of PLA/flax composites, despite showing lower molar mass, lowering of glass transition temperature, reduction of fibre length, and separation of fibre bundles with injection cycles, the property retention after three cycles under indicate the promising recyclability of these materials [121].

In another study, PLA / recycled wood fiber (RWF) composites with a small amount of silane were compounded using a kinetic-mixer and molded using an injection molding machine. Mechanical properties such as the strain-at-break also decreased with the RWF content. However, the tensile strength remained the same irrespective of the RWF content. As well, both the tensile modulus and the storage modulus of the PLA-RWF composites increased with the RWF content, in connection with an increase of crystallinity. Interestingly, no reduction in molar mass was observed for pure PLA and PLA-10\%RWF-0.5\%Silane composites after injection molding; however, substantial reduction in molar mass was found in PLA-20\%RWF-0.5\%Silane composites [122].

Other options have explored the possibility of grinding PLA-based biocomposites reinforced with kenaf fibers and rice husk, to be used in low-cost polymer-based mortars [123].

Sisal is one of the main natural fibres used to reinforced bio-based polymers[124]-[129]. Studies in composites of PLA with sisal fibers [130], [131] argued that the cause of the degradation could be ascribed to two main reasons: on the one hand, an increase in the crystallinity of the material, due to the nucleating effect of the presence of fibers and, on the other hand, a deterioration of the fiber interface with the matrix, which involve defects such as cracks, pores or flakes, with increasingly larger presence of fibers in the biocomposites. The use of recycled PLA in PLA-sisal composites has been reported[48] to improve biodegradability, which from the point of view of waste management can be of high interest. 


\section{COMBINED WASTE MANAGEMENT SOLUTIONS FOR RECYCLED PLA}

With the aim of enlarging the usability of PLAs before finally discarding them, it would be advisable to explore the possibilities of recovering, as well as extending their use during service life. Once reuse and mechanical recycling, both in-plant and postconsumed, have been exploited, other possibilities should be applied. Chemical, energetic and biological valorizations are particularly appointed for that purpose, as shown in Figure 11.

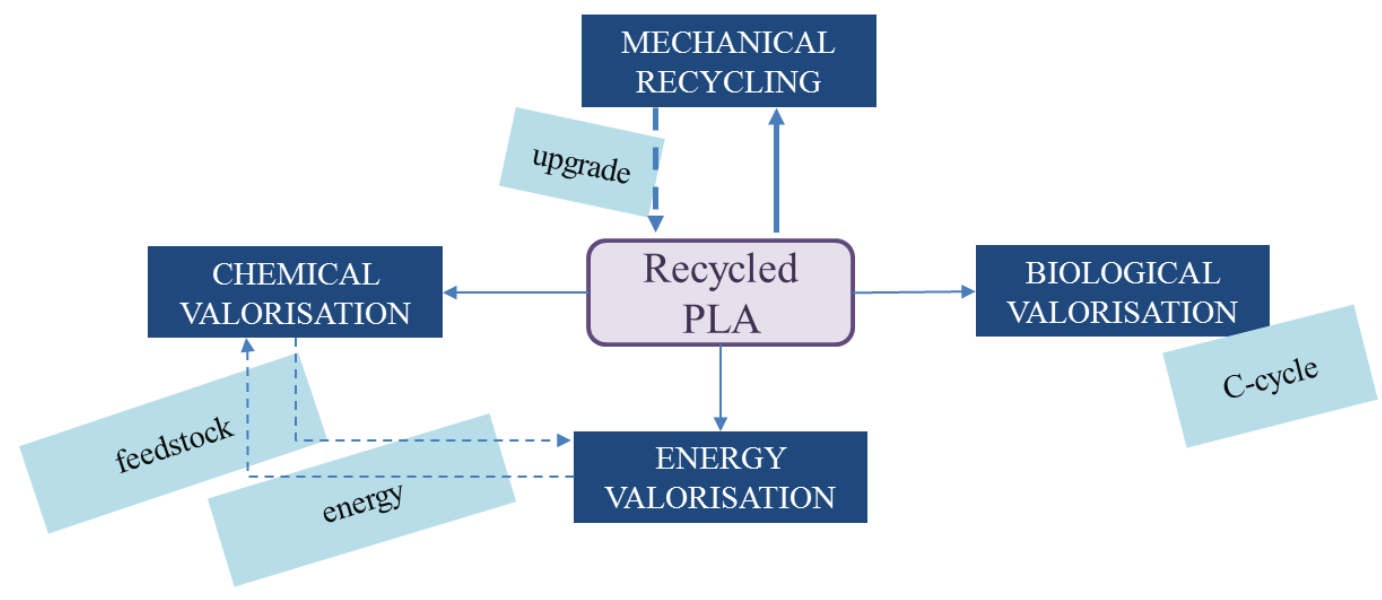

Figure 21. Schematic representation of valorisation options for recycled PLA

\subsection{Chemical valorization of recycled PLA}

The chemical valorization consists in the obtaining of chemical feedstock from solvolytic depolymerization processes [132]. Hydrolysis at high temperatures to obtain lactic acid [133]-[135] and thermal decomposition of PLA for preparing lactide [136]-[138] have been reported. The recycling efficiency [135] was found to be strongly dependent on operating conditions such as temperature, reaction time and the amount of water relative to the material to be recycled. The sustainability of chemical recycling to obtain lactic acid from an environmental point of view has been shown to be preferable, from an energetic point of view, to other options such as glucose fermentation. However, the study also showed that the environmental footprint of the analyzed process is larger than that of the PLA mechanical recycling[139]. 
The organocatalytic recycling of post-consumer polylactide (PLA) into added-value small molecules has been also reported [140] by the use of active transesterification catalyst triazabicyclodecene, which was shown to completely depolymerize PLA in the presence of various alcohols into lactate esters. The opportunities to transform waste streams into added-value feedstock and new materials through simple and versatile chemistry hold significant potential to extend the lifecycle of renewable chemical feedstocks.

Chemical recovery of commingled PLA-based blends rely on the selective reactivity to solvolysis, as reported for PLA/PE , PLA/PBS [107]. For instance, by solving the PLA/PE blends in toluene with montmorillonite, which is selective for PLA, producing low molar mass lactic acid oligomer, it can be separated from PE or PBS which remain unmodified and can be reprecipitated. As well, a promising method considering the separation of PLA from PLA/PET wastes by the use of zinc acetate to yield a liquid monomer from which the solid PET can be filtered [108].

Despite no reports have been found in literature for the combination of mechanical and chemical recycling, one may think that the operating conditions would slightly be influenced, since the chemical nature of the material after several reprocessing cycles is not severely affected [30].

\subsection{Energy valorization of recycled PLA}

Another viable solution to manage bioplastics waste when no more performance at good properties can be guaranteed by mechanical recycling is the application of thermallyinduced energetic recovery technologies, such as pyrolysis, gasification or combustion[141]. Also the obtaining of feedstock such is the case of lactide by microwave-assisted pyrolysis can be performed[142]. Several technologies are developed to optimize the energetic balance of the valorization processes by means of different facilities[13]. As well, the identification and quantification of gases[49], [50], [79], [143]-[145] is of extreme importance to design safe and environmentally-friendly facilities. 
In the selection of the operational parameters for the correct performance of the valorization, the knowledge of the thermal behavior of the materials is primary. Thermogravimetric analysis is a widely used technique to assess the decomposition kinetics of polymers under both inert and oxidative atmospheres [42]. The thermal simulation of the decomposition process of recycled PLA has been reported [49], [50]. It was found that PLA, as well as its successive 5 recyclates, described a mass-loss profile driven by one decomposition stage in inert conditions and two in oxidizing conditions. In both cases, the first step could be ascribed to the pyrolysis of the backbone, while the second mass-loss step under $\mathrm{O}_{2}$ was related to the decomposition of the remaining char, regardless the number of processing cycles.

Concerning the decomposition kinetics, it was found that the kinetic model that mathematically described the thermal and thermo-oxidative decompositions of PLA and their recyclates was of the type $A_{n}$ : nucleation and growth, which gave importance to the formation of gas bubbles in the melt[49], [50]. Focusing on each process, under inert atmosphere, the recyclates needed more energy and temperatures to decompose than virgin materials, whereas under $\mathrm{O}_{2}$ the decomposition of all recyclates was overcome at lower activation energy than that of virgin materials. Interestingly, the apparition of reaction sites liable to $\mathrm{O}_{2}$ in the PLA structure promoted the decomposition with less demanded energy from the third reprocessing cycle on, also pointing out the feasibility of combustion to valorise highly reprocessed polylactide. Thus, controlled combustion could be an option to valorise both materials energetically. All the considerations shown may provide technologist with plausible indicators for the selection of the adequate energetic recovery option of recycled PLA. Is was concluded that the necessary facilities for achieving the energetic valorization of reprocessed PLAs could thus be the same than those needed for virgin PLA, which may reduce costs of investing in new technologies. 


\subsection{Biological valorization of recycled PLA}

Biodegradation in soil of PLA has been reported to take several years, due to the low temperature and humidity conditions[42], [146]. However, PLA and their composites with natural fibers[48] are specially appointed to be compostable, since the temperatures in composting piles are over its glass transition and therefore eases its disintegration[147]-[150]. Enzymatic methodologies, claimed to be more efficient and economically competitive in comparison to other methods should also be taken into account [151].

Short information is available in literature for composting and/or biodegradation of reprocessed polylactide. Sikorska et al assessed the suitability of reprocessed PLA to be degraded under industrial composting conditions [64]. Several samples were buried in a static composting open-air pile which consisted in leaves, branches and grass at $\mathrm{pH}$ of $\sim 7.0$ and temperature of $\sim 60^{\circ} \mathrm{C}$. It was demonstrated that multi-reprocessing of PLA did not significantly affect the rate of biodegradation and only slightly affected to the disintegration progress of the PLA samples. Thus, composting facilities can be used not only for treating one-use PLA goods, which are certified for composting, but also its successive recyclates, which reduces the investment in further technologies of sorting and/or previous treatments.

\section{OVERVIEW AND OPPORTUNITIES}

Polylactides are progressively being introduced in the plastic chain and therefore will shortly represent a considerable fraction of polymer waste. As a first step, reduction in origin would imply the combination of eco-design approaches, bearing the entire life cycle in mind, but when the product is in the market, the valorization has to been taken into account in other terms. Thus, the efforts in ascertaining the recovery and/or valorization at the best quality conditions are a hot topic within scientists and technologists. Among all recovery methods, mechanical recycling of PLA represents one of the most cost-effective methodologies, but the recycled materials are usually directed to downgraded applications. This is due to the inherent thermo-mechanical degradation which mainly induces chain scissions and inter/intra - molecular transesterifications, affecting to the molar mass distribution and subsequently to its mechanical, thermal and rheological properties. 
In this sense, the application of upgrading strategies, such as physical treatments like thermal annealing, chemical modifications with stabilizers, antioxidants and chain extenders, and blending/compositing with other constituents has to be engaged. As well, the combination of several valorization methodologies, including material (e.g. reusing, recycling), chemical (e.g. solvolysis), energetic (e.g. pyrolysis, gasification, combustion) or biological (e.g. soil, composting, enzymatic) are of special interest, mainly when the quality of recycled products does not fit the required performance.

The field of mechanical recycling of PLA and the upgrading of recycled PLA still offers a wide field of opportunities. Some of them are listed hereby, as suggestions for further research and applications:

(i) To develop optical sensors at industrial-scale to improve the sorting of PLA wastes.

(ii) To improve the assurance of the quality of recycled PLA by a complete multi-scale validation, based on specific indicators of degradation and/or durability, mainly focusing on the structural assessment, in order to connect with the consequent performance.

(iii) To widen the knowledge on the control of enantiomeric distribution of PLA and their consequences on the recycling.

(iv) To picture the influence of low molecular weight compounds of the surroundings of disposal and during reprocessing, in terms of health and environmental effects.

(v) To explore the control of annealing treatments with a correct balance of desired properties and bearable drawbacks.

(vi) To strengthen the study of additives such as stabilizers, antioxidants and chain-extenders to be added during mechanical recycling of PLA

(vii) To improve the studies of addition, blending and compositing recycled PLA with itself, compatible polymers and/or specific fillers/fibers that upgrade the quality of these wastes. 
(viii) To promote the research and investment in the implementation of combined valorization techniques, mainly by chemical and/or energetic recycling after mechanical recycling, in order to obtain the optimal performance of each methodology, to ensure the highest extent of profit of PLA products.

(ix) To extent the studies of biodegradability of PLA, mixtures of PLA and recycled PLA with other commodities in pilot-scale and industrial-scale composting facilities, in order to close the entire life cycle with the lowest environmental impact.

Finally, one may note that most of the knowledge in the area of mechanical recycling of PLA has been built on results from experiments conducted on model materials at lab. Real PLA wastes coming from sorting facilities may undergo contamination by pollutants, and experience physic-chemical degradation by UV radiation, moisture, temperature, as well as started biodegradation, individually or in combination. Therefore, the study of the recycling of real PLA waste will be of special interest to assess the performance of recycled PLA goods and to envisage the potential of upgrading and/or the relevance of further valorizations.

\section{ACKNOWLEDGEMENTS}

The authors acknowledge the Spanish Ministry of Economy and Competitiveness for the projects POLYCELL (ENE2014-53734-C2-1-R) and TETRA-SEC (UPOV13-3E-1947). The Chilean Corporation for the Promotion of Productivity (CORFO) is thanked for the funding of project CEN-Chile (13CEI2-21839). Generalitat Valenciana is recognized for the BIOARMED project (APOSTD/2014/041) for J.D. Badia. 


\section{REFERENCES}

[1] C. Chassenieux, D. Durand, P. Jyotishkumar, and S. Thomas, "Biopolymers : State of the Art , New Challenges , and Opportunities,” pp. 1-6, 2013.

[2] K. Madhavan Nampoothiri, N. R. Nair, and R. P. John, "An overview of the recent developments in polylactide (PLA) research.,” Bioresour. Technol., vol. 101, no. 22, pp. 8493-501, Nov. 2010.

[3] A. J. R. Lasprilla, G. a R. Martinez, B. H. Lunelli, A. L. Jardini, and R. M. Filho, "Poly-lactic acid synthesis for application in biomedical devices - a review.," Biotechnol. Adv., vol. 30, no. 1, pp. 321-8, Jan. 2012.

[4] J. M. Anderson and M. S. Shive, "Biodegradation and biocompatibility of PLA and PLGA microspheres,” Adv. Drug Deliv. Rev., vol. 64, pp. 72-82, Dec. 2012.

[5] X. Xu, W. Zhong, S. Zhou, A. Trajtman, and M. Alfa, "Electrospun PEG - PLA Nanofibrous Membrane for Sustained Release of Hydrophilic Antibiotics,” J. Appl. Polym. Sci., 2010.

[6] P. Capra, B. Briasco, M. Sorrenti, L. Catenacci, M. Sachet, and P. Perugini, "Preliminary evaluation of packaging-content interactions: Mechanical and physicochemical characterization of polylactide bottles,” J. Appl. Polym. Sci., vol. 40067, p. n/a-n/a, Oct. 2013.

[7] V. Siracusa, I. Blanco, S. Romani, U. Tylewicz, P. Rocculi, and M. D. Rosa, "Poly ( lactic acid ) -Modified Films for Food Packaging Application: Physical, Mechanical , and Barrier Behavior,” J. Appl. Polym. Sci., no. Diim, 2012.

[8] G. E. Luckachan and C. K. S. Pillai, "Biodegradable Polymers- A Review on Recent Trends and Emerging Perspectives,” J. Polym. Environ., vol. 19, no. 3, pp. 637-676, Jun. 2011.

[9] C. R. Álvarez-Chávez, S. Edwards, R. Moure-Eraso, and K. Geiser, "Sustainability of bio-based plastics: general comparative analysis and recommendations for improvement,” J. Clean. Prod., vol. 23, no. 1, pp. 47-56, Mar. 2012.

[10] A. K. Mohanty, M. Misra, and G. Hinrichsen, "Biofibres, biodegradable polymers and biocomposites: An overview,” Macromol. Mater. Eng., vol. 276-277, pp. 124, 2000.

[11] S. Slomkowski, S. Penczek, and A. Duda, "Polylactides-an overview," Polym. Adv. Technol., vol. 2014, no. February, 2014.

[12] R. Auras, B. Harte, and S. Selke, "An overview of polylactides as packaging materials,” Macromol. Biosci., vol. 4, p. 835, 2004.

[13] J. D. Badia, "Strategies and analytical procedures for a sustainable plastic waste maangement. An application to poly(ethylene terephthalate) and polylactide in the packaging sector,” Universitat Politècnica de València, 2011.

[14] S. Papong, P. Malakul, R. Trungkavashirakun, P. Wenunun, T. Chom-in, M. Nithitanakul, and E. Sarobol, "Comparative assessment of the environmental profile of PLA and PET drinking water bottles from a life cycle perspective," $J$. Clean. Prod., Sep. 2013.

[15] T. a. Hottle, M. M. Bilec, and A. E. Landis, "Sustainability assessments of biobased polymers,” Polym. Degrad. Stab., vol. 98, no. 9, pp. 1898-1907, Sep. 2013. 
[16] J. a. Stagner, S. Tseng, and E. K. L. Tam, "Bio-Based Polymers and End-of-Life Vehicles,” J. Polym. Environ., vol. 20, no. 4, pp. 1046-1051, Jul. 2012.

[17] I. Leceta, a. Etxabide, S. Cabezudo, K. de la Caba, and P. Guerrero, "Bio-based films prepared with by-products and wastes: environmental assessment,” J. Clean. Prod., vol. 64, pp. 218-227, Feb. 2014.

[18] K. Hamad, M. Kaseem, and F. Deri, "Recycling of waste from polymer materials: An overview of the recent works,” Polym. Degrad. Stab., vol. 98, no. 12, pp. 28012812, Dec. 2013.

[19] A. Soroudi and I. Jakubowicz, "Recycling of bioplastics, their blends and biocomposites: A review,” Eur. Polym. J., vol. 49, no. 10, pp. 2839-2858, Oct. 2013.

[20] S. M. Al-Salem, P. Lettieri, and J. Baeyens, "Recycling and recovery routes of plastic solid waste (PSW): A review," Waste Manag., vol. 29, no. 10, pp. 26252643, Oct. 2009.

[21] F. Vilaplana and S. Karlsson, "Quality concepts for the improved use of recycled polymeric materials: A review,” Macromol. Mater. Eng., vol. 293, no. 4, pp. 274297, 2008.

[22] H. Kometani, T. Matsumura, T. Suga, and T. Kanai, "Quantitative analysis for polymer degradation in the extrusion process,” Int. Polym. Process., vol. 21, no. 1, pp. 24-31, 2006.

[23] S. Luzuriaga, J. Kováŕová, and I. Fortelný, "Degradation of pre-aged polymers exposed to simulated recycling: Properties and thermal stability,” Polym. Degrad. Stab., vol. 91, no. 6, pp. 1226-1232, 2006.

[24] A. M. Harris and E. C. Lee, "Durability of polylactide-based polymer blends for injection-molded applications,” J. Appl. Polym. Sci., vol. 125, pp. 4302-4315, Aug. 2012.

[25] A. M. Harris and E. C. Lee, "Heat and Humidity Performance of Injection Molded PLA for Durable Applications,” J. Appl. Polym. Sci., vol. 115, pp. 20-23, 2009.

[26] J. D. Badia, L. Santonja-Blasco, A. Martínez-Felipe, and A. Ribes-Greus, "Hygrothermal ageing of reprocessed polylactide," Polym. Degrad. Stab., vol. 97, no. 10, pp. 1881-1890, 2012.

[27] A. Jaszkiewicz, A. K. Bledzki, and A. Meljon, "Impact of Humid Environment on Structural and Mechanical Properties of Biobased Polylactide," Int. Polym. Process., vol. 30, no. 4, pp. 522-527, Aug. 2015.

[28] S. Dopico-García, A. Ares-Pernas, J. Otero-Canabal, M. Castro-López, J. M. López-Vilariño, V. González-Rodríguez, and M. J. Abad-López, "Insight into industrial PLA aging process by complementary use of rheology, HPLC, and MALDI,” Polym. Adv. Technol., vol. 24, no. 8, pp. 723-731, 2013.

[29] J. D. Badía, E. Strömberg, A. Ribes-Greus, and S. Karlsson, “A statistical design of experiments for optimizing the MALDI-TOF-MS sample preparation of polymers. An application in the assessment of the thermo-mechanical degradation mechanisms of poly (ethylene terephthalate),” Anal. Chim. Acta, vol. 692, no. 12, pp. 85-95, 2011. 
[30] J. D. Badía, E. Strömberg, A. Ribes-Greus, and S. Karlsson, “Assessing the MALDI-TOF MS sample preparation procedure to analyze the influence of thermo-oxidative ageing and thermo-mechanical degradation on poly (Lactide)," Eur. Polym. J., vol. 47, no. 7, pp. 1416-1428, 2011.

[31] F. Vilaplana, S. Karlsson, A. Ribes-Greus, C. Schade, and N. Nestle, "NMR relaxation reveals modifications in rubber phase dynamics during long-term degradation of high-impact polystyrene (HIPS),” Polymer (Guildf)., vol. 52, no. 6, pp. 1410-1416, 2011.

[32] F. Vilaplana, A. Ribes-Greus, and S. Karlsson, “Analytical strategies for the quality assessment of recycled high-impact polystyrene: A combination of thermal analysis, vibrational spectroscopy, and chromatography,” Anal. Chim. Acta, vol. 604, no. 1, pp. 18-28, 2007.

[33] D. Newman, E. Laredo, A. Bello, A. Grillo, J. L. Feijoo, and A. J. Muller, "Molecular mobilities in biodegradable poly(DL-lactide)/poly(-caprolactone) blends," Macromolecules, vol. 42, no. 14, pp. 5219-5225, 2009.

[34] J. D. Badia, E. Strömberg, S. Karlsson, and A. Ribes-Greus, "The role of crystalline, mobile amorphous and rigid amorphous fractions in the performance of recycled poly (ethylene terephthalate) (PET),” Polym. Degrad. Stab., vol. 97, no. 1, pp. 98-107, 2012.

[35] J. D. Badia, E. Strömberg, S. Karlsson, and A. Ribes-Greus, "Material valorisation of amorphous polylactide. Influence of thermo-mechanical degradation on the morphology, segmental dynamics, thermal and mechanical performance,” Polym. Degrad. Stab., vol. 97, no. 4, pp. 670-678, 2012.

[36] F. Vilaplana, S. Karlsson, and A. Ribes-Greus, "Changes in the microstructure and morphology of high-impact polystyrene subjected to multiple processing and thermo-oxidative degradation,” Eur. Polym. J., vol. 43, no. 10, pp. 4371-4381, 2007.

[37] J. Badia, L. Santonja-Blasco, A. Martínez-Felipe, and A. Ribes-Greus, "Dynamic Mechanical Thermal Analysis of Polymer Blends," in Characterization of Polymer Blends: Miscibility, Morphology, and Interfaces, First Edition., S. Thomas, Y. Grohens, and P. Jyotishkumar, Eds. Wiley-VCH Verlag GmbH \& Co. KGaA, 2014.

[38] J. D. Badia, L. Monreal, V. Sáenz de Juano-Arbona, and A. Ribes-Greus, “Dielectric spectroscopy of recycled polylactide,” Polym. Degrad. Stab., vol. 107, pp. 21-27, Sep. 2014.

[39] S. A. Cruz and M. Zanin, "Dielectric strength of the blends of virgin and recycled HDPE,” J. Appl. Polym. Sci., vol. 91, no. 3, pp. 1730-1735, 2004.

[40] F. Vilaplana, A. Ribes-Greus, and S. Karlsson, "Degradation of recycled highimpact polystyrene. Simulation by reprocessing and thermo-oxidation," Polym. Degrad. Stab., vol. 91, no. 9, pp. 2163-2170, 2006.

[41] J. D. Badía, F. Vilaplana, S. Karlsson, and A. Ribes-Greus, “Thermal analysis as a quality tool for assessing the influence of thermo-mechanical degradation on recycled poly(ethylene terephthalate),” Polym. Test., vol. 28, no. 2, pp. 169-175, 2009. 
[42] J. D. Badia, A. Martinez-Felipe, L. Santonja-Blasco, and A. Ribes-Greus, "Thermal and thermo-oxidative stability of reprocessed poly(ethylene terephthalate),” J. Anal. Appl. Pyrolysis, vol. 99, pp. 191-202, 2013.

[43] J. Möller, E. Strömberg, and S. Karlsson, "Comparison of extraction methods for sampling of low molecular compounds in polymers degraded during recycling," Eur. Polym. J., vol. 44, no. 6, pp. 1583-1593, Jun. 2008.

[44] C. Hopmann, S. Schippers, and C. H??fs, "Influence of recycling of poly(lactic acid) on packaging relevant properties,” J. Appl. Polym. Sci., vol. 132, no. 9, pp. 1-6, 2015.

[45] J. D. Badia, L. Monreal-Mengual, V. Sáenz de Juano, and A. Ribes-Greus, “DIELECTRIC SPECTROSCOPY OF RECYCLED POLYLACTIDE,” Polym. Degrad. Stab., vol. 107, pp. 21-27, 2014.

[46] Z. Xi, O. R. Ghita, and K. E. Evans, "Effect of recyclate PTFE/GF laminate incorporation on the dielectric and mechanical properties of PTFE/GF composites using a novel manufacturing process,” J. Appl. Polym. Sci., vol. 122, no. 4, pp. 2467-2477, 2011.

[47] T. Kijchavengkul and R. Auras, “Compostability of polymers,” Polym. Int., vol. 57, no. 6, pp. 793-804, 2008.

[48] C.-S. Wu, "Preparation, characterization, and biodegradability of renewable resource-based composites from recycled polylactide bioplastic and sisal fibers," J. Appl. Polym. Sci., vol. 123, no. 1, pp. 347-355, 2012.

[49] J. D. Badia, L. Santonja-Blasco, a Martínez-Felipe, and A. Ribes-Greus, “A methodology to assess the energetic valorization of bio-based polymers from the packaging industry: Pyrolysis of reprocessed polylactide,” Bioresour. Technol., vol. 111, pp. 468-475, Jul. 2012.

[50] J. D. Badia, L. Santonja-Blasco, a Martínez-Felipe, and A. Ribes-Greus, "Reprocessed polylactide: studies of thermo-oxidative decomposition.," Bioresour. Technol., vol. 114, pp. 622-8, Jul. 2012.

[51] J. M. Encinar and J. F. González, "Pyrolysis of synthetic polymers and plastic wastes. Kinetic study,” Fuel Process. Technol., vol. 89, no. 7, pp. 678-686, Jul. 2008.

[52] E. Strömberg and S. Karlsson, "Photo- And thermo-oxidation of polypropylene, Recycled polypropylene and polylactide biocomposites in a microenvironment chamber,” Polym. from Renew. Resour., vol. 1, no. 1, pp. 1-15, 2010.

[53] E. Strömberg and S. Karlssom, "The design of a test protocol to model the degradation of polyolefirts during eecycling and service life,” J. Appl. Polym. Sci., vol. 112, no. 3, pp. 1835-1844, 2009.

[54] F. Vilaplana, M. Martínez-Sanz, A. Ribes-Greus, and S. Karlsson, "Emission pattern of semi-volatile organic compounds from recycled styrenic polymers using headspace solid-phase microextraction gas chromatography-mass spectrometry," J. Chromatogr. A, vol. 1217, no. 3, pp. 359-367, 2010.

[55] F. Vilaplana, A. Ribes-Greus, and S. Karlsson, "Chromatographic pattern in recycled high-impact polystyrene (HIPS) - Occurrence of low molecular weight compounds during the life cycle,” Polym. Degrad. Stab., vol. 95, no. 2, pp. 172186, 2010. 
[56] F. P. La Mantia and M. Vinci, "Recycling poly(ethyleneterephthalate)," Polym. Degrad. Stab., vol. 45, no. 1, pp. 121-125, 1994.

[57] N. Yarahmadi, I. Jakubowicz, and T. Gevert, "Effects of repeated extrusion on the properties and durability of rigid PVC scrap,” Polym. Degrad. Stab., vol. 73, no. 1, pp. 93-99, 2001.

[58] B. Itim and M. Philip, "Effect of multiple extrusions and influence of PP contamination on the thermal characteristics of bottle grade recycled PET," Polym. Degrad. Stab., vol. 117, pp. 84-89, Jul. 2015.

[59] M. del M. C. López, A. I. Ares Pernas, M. J. Abad López, A. L. Latorre, J. M. López Vilariño, and M. V. González Rodríguez, "Assessing changes on poly(ethylene terephthalate) properties after recycling: Mechanical recycling in laboratory versus postconsumer recycled material,” Mater. Chem. Phys., vol. 147, no. 3, pp. 884-894, Oct. 2014.

[60] K. Moraczewski, "Influence of multiple processing on selected properties of poly(3-hydroxybutyrate- co -4-hydroxybutyrate),” Polym. Adv. Technol., vol. 27, no. 6, pp. 733-739, 2016.

[61] K. Moraczewski, "Characterization of multi-injected poly( $\varepsilon$-caprolactone)," Polym. Test., vol. 33, pp. 116-120, Feb. 2014.

[62] I. Pillin, N. Montrelay, A. Bourmaud, and Y. Grohens, "Effect of thermomechanical cycles on the physico-chemical properties of poly(lactic acid)," Polym. Degrad. Stab., vol. 93, no. 2, pp. 321-328, Feb. 2008.

[63] M. Żenkiewicz, J. Richert, P. Rytlewski, K. Moraczewski, M. Stepczyńska, and T. Karasiewicz, "Characterisation of multi-extruded poly(lactic acid)," Polym. Test., vol. 28, no. 4, pp. 412-418, Jun. 2009.

[64] W. Sikorska, J. Richert, J. Rydz, M. Musioł, G. Adamus, H. Janeczek, and M. Kowalczuk, "Degradability studies of poly(l-lactide) after multi-reprocessing experiments in extruder,” Polym. Degrad. Stab., vol. 97, no. 10, pp. 1891-1897, Oct. 2012.

[65] F. Carrasco, P. Pagès, J. Gámez-Pérez, O. O. Santana, and M. L. Maspoch, "Processing of poly(lactic acid): Characterization of chemical structure, thermal stability and mechanical properties,” Polym. Degrad. Stab., vol. 95, no. 2, pp. 116125, Feb. 2010.

[66] B. Brüster, F. Addiego, F. Hassouna, D. Ruch, J.-M. Raquez, and P. Dubois, "Thermo-mechanical degradation of plasticized poly(lactide) after multiple reprocessing to simulate recycling: Multi-scale analysis and underlying mechanisms,” Polym. Degrad. Stab., vol. 131, pp. 132-144, 2016.

[67] N. Yarahmadi, I. Jakubowicz, and J. Enebro, "Polylactic acid and its blends with petroleum-based resins: Effects of reprocessing and recycling on properties," $J$. Appl. Polym. Sci., vol. 43916, pp. 1-9, 2016.

[68] H. Sirin, B. Tuna, and G. Ozkoc, "The effects of thermomechanical cycles on the properties of PLA/TPS blends,” Adv. Polym. Technol., vol. 33, no. S1, pp. 1-9, 2014. 
[69] I. Zembouai, S. Bruzaud, M. Kaci, A. Benhamida, Y. M. Corre, Y. Grohens, A. Taguet, and J. M. Lopez-Cuesta, "Poly(3-Hydroxybutyrate-co-3Hydroxyvalerate)/Polylactide Blends: Thermal Stability, Flammability and Thermo-Mechanical Behavior,” J. Polym. Environ., vol. 22, no. 1, pp. 131-139, 2014.

[70] F. Carrasco, P. Pagès, J. Gámez-Pérez, O. O. Santana, and M. L. Maspoch, "Kinetics of the thermal decomposition of processed poly(lactic acid)," Polym. Degrad. Stab., vol. 95, no. 12, pp. 2508-2514, Dec. 2010.

[71] G. Kister, G. Cassanas, and M. Vert, "Effects of morphology, conformation and configuration on the IR and Raman spectra of various poly(lactic acid)s," Polymer (Guildf)., vol. 39, no. 2, pp. 267-273, Jan. 1998.

[72] R. Pantani, F. De Santis, a. Sorrentino, F. De Maio, and G. Titomanlio, "Crystallization kinetics of virgin and processed poly(lactic acid)," Polym. Degrad. Stab., vol. 95, no. 7, pp. 1148-1159, Jul. 2010.

[73] M. Yasuniwa, S. Tsubakihara, Y. Sugimoto, and C. Nakafuku, "Thermal Analysis of the Double-Melting Behavior of Poly ( L -lactic acid ),” pp. 31-33, 2004.

[74] M. Yasuniwa, K. Iura, and Y. Dan, "Melting behavior of poly(l-lactic acid): Effects of crystallization temperature and time," Polymer (Guildf)., vol. 48, no. 18, pp. 5398-5407, Aug. 2007.

[75] M. Yasuniwa, K. Sakamo, Y. Ono, and W. Kawahara, "Melting behavior of poly(llactic acid): X-ray and DSC analyses of the melting process,” Polymer (Guildf)., vol. 49, no. 7, pp. 1943-1951, Apr. 2008.

[76] L. Santonja-Blasco, R. Moriana, J. D. Badía, and A. Ribes-Greus, "Thermal analysis applied to the characterization of degradation in soil of polylactide: II. on the thermal stability and thermal decomposition kinetics," Polym. Degrad. Stab., vol. 95, no. 11, pp. 2192-2199, 2010.

[77] L. Nascimento, J. Gamez-Perez, O. O. Santana, J. I. Velasco, M. L. Maspoch, and E. Franco-Urquiza, "Effect of the Recycling and Annealing on the Mechanical and Fracture Properties of Poly(Lactic Acid),” J. Polym. Environ., vol. 18, no. 4, pp. 654-660, Jul. 2010.

[78] P. Rizzarelli and S. Carroccio, "Modern mass spectrometry in the characterization and degradation of biodegradable polymers.,” Anal. Chim. Acta, vol. 808, pp. 1843, Jan. 2014.

[79] I. C. McNeill and H. A. Leiper, "Degradation studies of some polyesters and polycarbonates 1. Polylactide: general features of the degradation under programmed heating conditions,” Polym. Degrad. Stab., vol. 11, pp. 267-285, 1985.

[80] I. C. McNeill and H. A. Leiper, "Degradation studies of some polyesters and polycarbonates 2. Polylactide: degradation under isothermal conditions, thermal degradation mechanism and photolysis of the polymer," Polym. Degrad. Stab., vol. 11, pp. 309-326, 1985.

[81] F. D. Kopinke, M. Remmler, K. Mackenzie, M. Moder, and O. Wachsen, “Thermal decomposition of biodegradable polyesters. 2. Poly(lactic acid),” Polym. Degrad. Stab., vol. 53, pp. 329-342, 1996. 
[82] L. Santonja-Blasco, a. Ribes-Greus, and R. G. Alamo, "Comparative thermal, biological and photodegradation kinetics of polylactide and effect on crystallization rates,” Polym. Degrad. Stab., vol. 98, no. 3, pp. 771-784, Mar. 2013.

[83] O. Gil-Castell, J. D. Badia, R. Teruel-Juanes, I. Rodriguez, F. Meseguer, and A. Ribes-Greus, "Novel silicon microparticles to improve sunlight stability of raw polypropylene,” Eur. Polym. J., vol. 70, pp. 247-261, 2015.

[84] S. F, C. MB, and B. S., "Thermal degradation of poly(lactic acid) (PLA) and poly(butylene adipate-co-terephthalate) (PBAT) and their blends upon melt processing,” Polym. Degrad. Stab., vol. 94, pp. 74-82, 2009.

[85] J. K, H. SH, and I. Y, “Thermal characterization of polylactides.," Polymer (Guildf)., vol. 29, no. 12, pp. 2229-2234, 1988.

[86] A. Södergard and J. H. Näsman, "Stabilization of poly(L-lactide) in the melt," Polym. Degrad. Stab., vol. 49, no. 1, pp. 25-30, 1994.

[87] A. Jaszkiewicz, A. K. Bledzki, A. Duda, A. Galeski, and P. Franciszczak, "Investigation of processability of chain-extended polylactides during melt processing - Compounding conditions and polymer molecular structure," Macromol. Mater. Eng., vol. 299, no. 3, pp. 307-318, 2014.

[88] J. M. Julien, J.-C. Quantin, J.-C. Bénézet, A. Bergeret, M. F. Lacrampe, and P. Krawczak, "Chemical foaming extrusion of poly(lactic acid) with chain-extenders: Physical and morphological characterizations,” Eur. Polym. J., vol. 67, pp. 40-49, Jun. 2015.

[89] R. Khankrua, S. Pivsa-Art, H. Hiroyuki, and S. Suttiruengwong, "Effect of chain extenders on thermal and mechanical properties of poly(lactic acid) at high processing temperatures: Potential application in PLA/Polyamide 6 blend," Polym. Degrad. Stab., vol. 108, pp. 232-240, Oct. 2014.

[90] R. M. Michell, A. J. Müller, A. Boschetti-de-Fierro, D. Fierro, V. Lison, J.-M. Raquez, and P. Dubois, "Novel poly(ester-urethane)s based on polylactide: From reactive extrusion to crystallization and thermal properties," Polymer (Guildf)., vol. 53, no. 25, pp. 5657-5665, Nov. 2012.

[91] R. Al-Itry, K. Lamnawar, and A. Maazouz, "Improvement of thermal stability, rheological and mechanical properties of PLA, PBAT and their blends by reactive extrusion with functionalized epoxy,” Polym. Degrad. Stab., vol. 97, no. 10, pp. 1898-1914, Oct. 2012.

[92] L. Gouissem, A. Douibi, and D. Benachour, "The evolution of properties of recycled poly(ethylene terephthalate) as function of chain extenders, the extrusion cycle and heat treatment,” Polym. Sci. Ser. A, vol. 56, no. 6, pp. 844-855, 2014.

[93] M. Oliveira, E. Santos, A. Araújo, G. J. M. Fechine, A. V. Machado, and G. Botelho, "The role of shear and stabilizer on PLA degradation," Polym. Test., vol. 51, pp. 109-116, May 2016.

[94] N. S. Q. S. Amorin, G. Rosa, J. F. Alves, S. P. C. Gonçalves, S. M. M. Franchetti, and G. J. M. Fechine, "Study of thermodegradation and thermostabilization of poly(lactide acid) using subsequent extrusion cycles,” J. Appl. Polym. Sci., vol. 131, no. 6, p. n/a-n/a, Mar. 2014. 
[95] X. Meng, G. Shi, W. Chen, C. Wu, Z. Xin, T. Han, and Y. Shi, "Structure effect of phosphite on the chain extension in PLA,” Polym. Degrad. Stab., vol. 120, pp. 283-289, Oct. 2015.

[96] X. Meng, G. Shi, C. Wu, W. Chen, Z. Xin, Y. Shi, and Y. Sheng, “Chain extension and oxidation stabilization of Triphenyl Phosphite (TPP) in PLA,” Polym. Degrad. Stab., vol. 124, pp. 112-118, Feb. 2016.

[97] A. Araújo, G. Botelho, M. Oliveira, and A. V. Machado, "Influence of clay organic modifier on the thermal-stability of PLA based nanocomposites," Appl. Clay Sci., vol. 88-89, pp. 144-150, Feb. 2014.

[98] D. Bendahou, A. Bendahou, Y. Grohens, and H. Kaddami, "New nanocomposite design from zeolite and poly(lactic acid),” Ind. Crops Prod., vol. 72, pp. 107-118, Oct. 2015.

[99] B. S. Bouakaz, I. Pillin, A. Habi, and Y. Grohens, "Synergy between fillers in organomontmorillonite/graphene-PLA nanocomposites,” Appl. Clay Sci., vol. 116-117, pp. 69-77, Nov. 2015.

[100] Y. Byun, K. Rodriguez, J. H. Han, and Y. T. Kim, "Improved thermal stability of polylactic acid (PLA) composite film via PLA- $\beta$-cyclodextrin-inclusion complex systems.,” Int. J. Biol. Macromol., vol. 81, pp. 591-8, Nov. 2015.

[101] B. Imre and B. Pukánszky, "Compatibilization in bio-based and biodegradable polymer blends,” Eur. Polym. J., vol. 49, no. 6, pp. 1215-1233, Jun. 2013.

[102] H. Liu and J. Zhang, "Research progress in toughening modification of poly(lactic acid),” J. Polym. Sci. Part B Polym. Phys., vol. 49, no. 15, pp. 1051-1083, Aug. 2011.

[103] R. Scaffaro, M. Morreale, F. Mirabella, and F. P. La Mantia, "Preparation and Recycling of Plasticized PLA,” Macromol. Mater. Eng., vol. 296, no. 2, pp. 141150, Feb. 2011.

[104] D. Helfenbein, "Development of recycling of PLA sheet into PLA pellets without undergoing chemical process,” Atlanta, GA, 2011.

[105] M. Naitove, “Bioplastics are breaking out of their 'green' niche.,” Plast. Technol., vol. 58, no. 4, pp. 13-17 + 58-62, 2012.

[106] a. Ulrici, S. Serranti, C. Ferrari, D. Cesare, G. Foca, and G. Bonifazi, "Efficient chemometric strategies for PET-PLA discrimination in recycling plants using hyperspectral imaging," Chemom. Intell. Lab. Syst., vol. 122, pp. 31-39, Mar. 2013.

[107] Y. Tsuneizumi, M. Kuwahara, K. Okamoto, and S. Matsumura, "Chemical recycling of poly(lactic acid)-based polymer blends using environmentally benign catalysts,” Polym. Degrad. Stab., vol. 95, no. 8, pp. 1387-1393, Aug. 2010.

[108] A. Carné Sanchez, S. R. Collinson, A. C. Sánchez, and S. R. Collinson, "The selective recycling of mixed plastic waste of polylactic acid and polyethylene terephthalate by control of process conditions,” Eur. Polym. J., vol. 47, no. 10, pp. 1970-1976, 2011.

[109] K. Hamad, M. Kaseem, and F. Deri, "Rheological and mechanical properties of poly(lactic acid)/polystyrene polymer blend,” Polym. Bull., vol. 65, no. 5, pp. 509519, Jul. 2010. 
[110] G. Biresaw and C. J. Carriere, "Compatibility and mechanical properties of blends of polystyrene with biodegradable polyesters,” Compos. Part A Appl. Sci. Manuf., vol. 35, no. 3, pp. 313-320, Mar. 2004.

[111] K. Hamad, M. Kaseem, and F. Deri, "Effect of recycling on rheological and mechanical properties of poly(lactic acid)/polystyrene polymer blend,” J. Mater. Sci., vol. 46, no. 5, pp. 3013-3019, Dec. 2010.

[112] S.-M. Lai, S.-H. Wu, G.-G. Lin, and T.-M. Don, "Unusual mechanical properties of melt-blended poly(lactic acid) (PLA)/clay nanocomposites,” Eur. Polym. J., vol. 52, pp. 193-206, Mar. 2014.

[113] A. F. Koutsomitopoulou, J. C. Bénézet, A. Bergeret, and G. C. Papanicolaou, "Preparation and characterization of olive pit powder as a filler to PLA-matrix biocomposites,” Powder Technol., vol. 255, pp. 10-16, Mar. 2014.

[114] N. Najafi, M. C. Heuzey, and P. J. Carreau, "Polylactide (PLA)-clay nanocomposites prepared by melt compounding in the presence of a chain extender,” Compos. Sci. Technol., vol. 72, no. 5, pp. 608-615, Mar. 2012.

[115] N. Najafi, M.-C. Heuzey, P. J. Carreau, D. Therriault, and C. B. Park, "Mechanical and morphological properties of injection molded linear and branched-polylactide (PLA) nanocomposite foams,” Eur. Polym. J., vol. 73, pp. 455-465, Dec. 2015.

[116] V. Srebrenkoska, G. Bogoeva-Gaceva, and D. Dimeski, "Biocomposites based on polylactic acid and their thermal behavior after recycling," Maced. J. Chem. Chem. Eng., vol. 33, no. 2, pp. 277-285, 2014.

[117] T. Mukherjee and N. Kao, "PLA based biopolymer reinforced with natural fibre: a review,” J. Polym. Environ., vol. 19, no. 3, pp. 714-725, 2011.

[118] D. Åkesson, T. Vrignaud, C. Tissot, and M. Skrifvars, "Mechanical Recycling of PLA Filled with a High Level of Cellulose Fibres,” J. Polym. Environ., 2016.

[119] F. Vilaplana, E. Strömberg, and S. Karlsson, "Environmental and resource aspects of sustainable biocomposites,” Polym. Degrad. Stab., vol. 95, no. 11, pp. 21472161, 2010.

[120] J. P. Lopez, J. Girones, J. a. Mendez, J. Puig, and M. a. Pelach, "Recycling Ability of Biodegradable Matrices and Their Cellulose-Reinforced Composites in a Plastic Recycling Stream,” J. Polym. Environ., vol. 20, no. 1, pp. 96-103, Jul. 2011.

[121] A. Le Duigou, I. Pillin, A. Bourmaud, P. Davies, and C. Baley, "Effect of recycling on mechanical behaviour of biocompostable flax/poly(l-lactide) composites," Compos. Part A Appl. Sci. Manuf., vol. 39, no. 9, pp. 1471-1478, Sep. 2008.

[122] S. Pilla, S. Gong, and E. O’Neill, "Polylactide-recycled wood fiber composites," J. Appl. ..., vol. 111, pp. 37-47, 2009.

[123] A. Grozdanov, M. Avella, A. Buzarovska, G. Gentile, and M. M. E. Errico, “euse of natural fiber reinforced eco-composites in polymer mortars," Polym. Eng. Sci., vol. 50, no. 4, pp. 762-766, Apr. 2010.

[124] J. D. Badia, T. Kittikorn, E. Strömberg, L. Santonja-Blasco, A. Martínez-Felipe, A. Ribes-Greus, M. Ek, and S. Karlsson, "Water absorption and hydrothermal performance of PHBV/sisal biocomposites,” Polym. Degrad. Stab., vol. 108, pp. 166-174, Oct. 2014. 
[125] V. A. Alvarez and A. Vázquez, "Thermal degradation of cellulose derivatives/starch blends and sisal fibre biocomposites,” Polym. Degrad. Stab., vol. 84, no. 1, pp. 13-21, Apr. 2004.

[126] V. A. Alvarez, R. A. Ruseckaite, and A. Vázquez, "Degradation of sisal fibre/Mater Bi-Y biocomposites buried in soil,” Polym. Degrad. Stab., vol. 91, no. 12, pp. 3156-3162, 2006.

[127] C. R. di Franco, V. P. Cyras, J. P. Busalmen, R. A. Ruseckaite, and A. Vázquez, "Degradation of polycaprolactone/starch blends and composites with sisal fibre," Polym. Degrad. Stab., vol. 86, no. 1, pp. 95-103, 2004.

[128] R. Moriana, F. Vilaplana, S. Karlsson, and A. Ribes-Greus, "Improved thermomechanical properties by the addition of natural fibres in starch-based sustainable biocomposites,” Compos. Part A Appl. Sci. Manuf., vol. 42, no. 1, pp. 30-40, 2011.

[129] R. Moriana, S. Karlsson, and A. Ribes-Greus, "Assessing the influence of cotton fibers on the degradation in soil of a thermoplastic starch-based biopolymer," Polym. Compos., vol. 31, no. 12, pp. 2102-2111, 2010.

[130] O. Gil-Castell, J. Badia, T. Kittikorn, E. Strömberg, A. Martínez-Felipe, M. Ek, S. Karlsson, and A. Ribes-Greus, "Hydrothermal ageing of polylactide/sisal biocomposites. Studies of water absorption behaviour and physicochemical performance,” Polym. Degrad. Stab., vol. In press.

[131] O. Gil-Castell, J. D. Badia, T. Kittikorn, E. Strömberg, M. Ek, S. Karlsson, and A. Ribes-Greus, "Impact of hydrothermal ageing on the thermal stability, morphology and viscoelastic performance of PLA/sisal biocomposites,” Polym. Degrad. Stab., 2016. doi:10.1016/j.polymdegradstab.2016.03.038

[132] G. Fleischer, F. Habashi, G. Menges, B. Bilitewski, and U. Loll, "Waste 5. Recycling," in Ullmann'sencyclopedia of industrial chemistry, Wiley-VCH Verlag GmbH \& Co. KGaA, 2000.

[133] A.-F. A. Mohd-Adnan, H. Nishida, and Y. Shirai, "Evaluation of kinetics parameters for poly(l-lactic acid) hydrolysis under high-pressure steam," Polym. Degrad. Stab., vol. 93, no. 6, pp. 1053-1058, Jun. 2008.

[134] H. Tsuji, H. Daimon, and K. Fujie, "A new strategy for recycling and preparation of poly(L-lactic acid): hydrolysis in the melt,” Biomacromolecules, vol. 4, no. 3, pp. 835-840, May 2003.

[135] M. Faisal, T. Saeki, H. Tsuji, H. Daimon, and K. Fujie, "Recycling of poly lactic acid into lactic acid with high temperature and high pressure water.," Trans. Ecol. Environ., vol. 92, pp. 225-233, 2006.

[136] H. Nishida, Y. Fan, T. Mori, N. Oyagi, Y. Shirai, and T. Endo, "Feedstock recycling of flame-resisting poly(lactic acid)/aluminum hydroxide composite to L,L-lactide.,” Ind. Eng. Chem. Res., vol. 44, no. 5, pp. 1433-1437, 2005.

[137] Y. Fan, H. Nishida, T. Mori, Y. Shirai, and T. Endo, "Thermal degradation of poly(L-lactide): Effect of alkali earth metal oxides for selective L,Llactide formation,” Polymer (Guildf)., vol. 45, no. 4, pp. 1197-1205, 2004.

[138] L. Ying, W. Rongqing, W. Jun, and L. Xiaoning, "Thermal degradation of poly(Llactide) with high molecular weight into Llactide,” Prog. Chem., vol. 20, no. 10, pp. 1588-1594, 2008. 
[139] V. Piemonte, S. Sabatini, and F. Gironi, "Chemical Recycling of PLA: A Great Opportunity Towards the Sustainable Development?,” J. Polym. Environ., vol. 21, no. 3, pp. 640-647, 2013.

[140] F. Leibfarth, N. Moreno, A. HAwker, and J. Shand, “Transforming polylactide into value-added materials,” J. Polym. Sci. Part A Polym. Chem., vol. 50, no. 23, pp. 4814-4822, 2012.

[141] V. Piemonte, "Bioplastic Wastes: The Best Final Disposition for Energy Saving,” J. Polym. Environ., vol. 19, no. 4, pp. 988-994, 2011.

[142] A. Undri, L. Rosi, M. Frediani, and P. Frediani, "Conversion of poly(lactic acid) to lactide via microwave assisted pyrolysis,” J. Anal. Appl. Pyrolysis, vol. 110, pp. 55-65, Nov. 2014.

[143] M. P. Arrieta, F. Parres, J. López, and A. Jiménez, "Development of a novel pyrolysis-gas chromatography/mass spectrometry method for the analysis of poly(lactic acid) thermal degradation products,” J. Anal. Appl. Pyrolysis, vol. 101, pp. 150-155, May 2013.

[144] F.-D. Kopinke and K. Mackenzie, "Mechanistic aspects of the thermal degradation of poly(lactic acid) and poly( $\beta$-hydroxybutyric acid)," J. Anal. Appl. Pyrolysis, vol. 40-41, pp. 43-53, May 1997.

[145] F.-D. Kopinke, M. Remmler, K. Mackenzie, M. Möder, and O. Wachsen, "Thermal decomposition of biodegradable polyesters-II. Poly(lactic acid)," Polym. Degrad. Stab., vol. 53, no. 3, pp. 329-342, Sep. 1996.

[146] L. Santonja-Blasco, R. Moriana, J. D. D. Badía, and A. Ribes-Greus, “Thermal analysis applied to the characterization of degradation in soil of polylactide: I. Calorimetric and viscoelastic analyses,” Polym. Degrad. Stab., vol. 95, no. 11, pp. 2192-2199, 2010.

[147] G. Kale, R. Auras, S. P. Singh, and R. Narayan, "Biodegradability of polylactide bottles in real and simulated composting conditions,” Polym. Test., vol. 26, no. 8, pp. 1049-1061, Dec. 2007.

[148] V. M. Ghorpade, A. Gennadios, and M. A. Hanna, "Laboratory composting of extruded poly(lactic acid) sheets,” Bioresource technology;76, 57-61, 2001.

[149] R. Pradhan, M. Misra, L. Erickson, and A. Mohanty, "Compostability and biodegradation study of PLA-wheat straw and PLA-soy straw based green composites in simulated composting bioreactor," Bioresource technology;101, 8489-8491, 2010.

[150] W. Sikorska, P. Dacko, M. Sobota, J. Rydz, M. Musioł, and M. Kowalczuk, "Degradation Study of Polymers from Renewable Resources and their Compositions in Industrial Composting Pile,” Macromol. Symp., vol. 272, no. 1, pp. 132-135, 2008.

[151] A. Jarerat, Y. Tokiwa, and H. Tanaka, "Production of poly(L-lactide) degrading enzyme by Amycolatopsis orientalis for biological recycling of poly(L-lactide).," Appl. Microbiol. Biotechnol., vol. 72, pp. 726-731, 2006. 
J.D. Badia, A. Ribes-Greus. Mechanical recycling of polylactide, upgrading trends and combination of valorisation techniques. European Polymer Journal, 2016; 84:22-39

\section{Annex. Open-access policies}

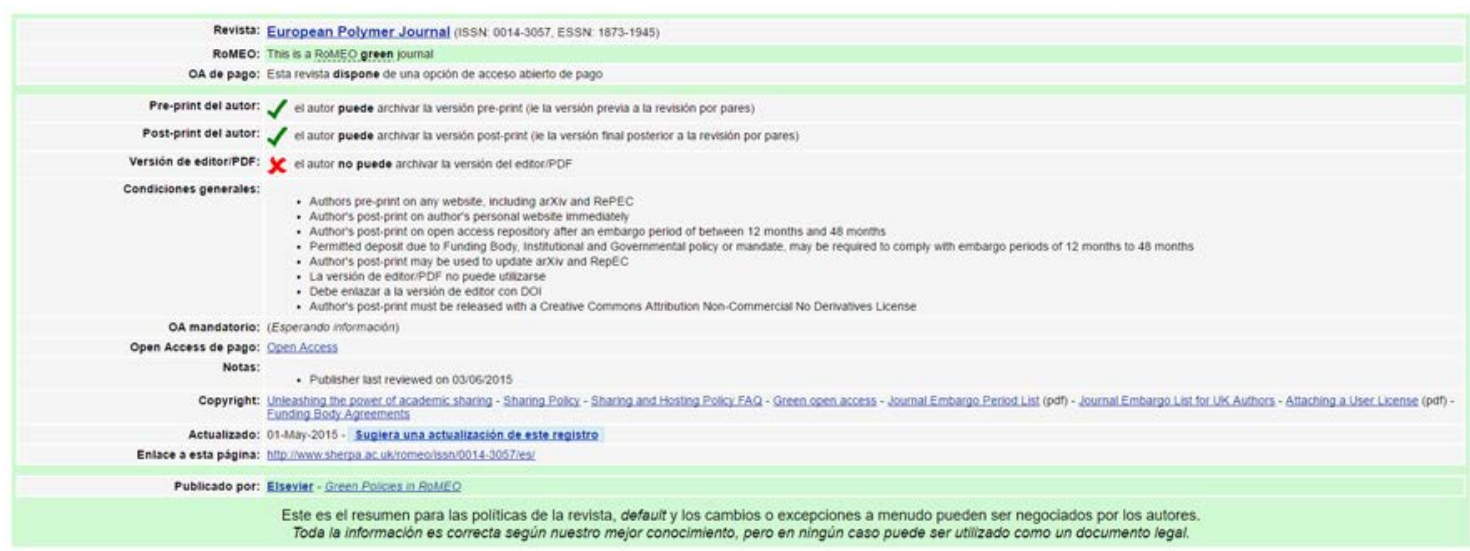

